IFN Working Paper No. 844, 2010

\title{
Exhaustible Resources, Technology Choice and Industrialization of Developing Countries
}

Erika Färnstrand Damsgaard 


\title{
Exhaustible Resources, Technology Choice and Industrialization of Developing Countries
}

\author{
Erika Färnstrand Damsgaard *
}

October 24, 2011

\begin{abstract}
How should the world economy adapt to the increased demand for exhaustible resources from countries like China and India? To address that issue, this paper presents a dynamic model of the world economy with two technologies for production; a resource technology, which uses an exhaustible resource as an input and an alternative technology, which does not. I find that both the time path of resource extraction and the adoption of the alternative technology depend on the optimal allocation of capital across the technologies, and on the size of the capital stock in relation to the resource stock. In particular, if the capital stock is low, only the resource technology is used initially and the alternative technology is adopted with a delay. Next, I use the model to analyze the effects of industrialization of developing countries on the extraction of oil and technology choice for energy production. As a result of industrialization, the alternative technology for energy production is adopted earlier.
\end{abstract}

JEL-codes: Q30, Q40

Keywords: Exhaustible resources, Technological change

${ }^{*}$ Research Institute of Industrial Economics. P.O Box 55665, SE-10215 Stockholm, Sweden. Tel: +46 8 6654557. Fax: +4686654599. E-mail: erika.farnstrand.damsgaard@ifn.se. 


\section{Introduction}

In recent years, the industrialization of large developing countries such as China and India has generated a considerable increase in demand for exhaustible resources, for example copper, aluminum, iron ore and oil. ABARE (2008) reports that China and India accounted for about 35 percent of global steel consumption in 2007 and China alone accounted for about one third of world consumption of aluminum. Between 1990 and 2006, China's and India's total oil consumption increased by about 180 percent. ${ }^{1}$ The increase in resource use has resulted in increases in the extraction of resources and through higher resource prices it has had an impact on resource-importing countries in the rest of the world.

"China's hunger for natural resources has set off a global commodity boom. Developed countries worry about being left high and dry"

The Economist, March 13th 2008

A study by Gordon et al. (2006) estimates that the global stock of copper is insufficient to make the standard of developed countries available to the total world population. Using data on per person copper use in countries such as the US, the authors find that extending that use to the world population requires more copper than even the most generous estimate of available resources. They find that the same holds for zinc, and possibly aluminum. Several studies of this kind have contributed to a renewed interest in the management of exhaustible resources from academics as well as from policymakers. In light of the possibility that demand exceeds total supply, at what rate should these exhaustible resources be extracted? When will exhaustible resources be substituted for renewable resources and how will the transition take place? In an attempt to address such issues from an optimal policy perspective, this paper constructs a dynamic model of the world economy that exhibits two production technologies; a resource technology which uses an exhaustible resource as input, and an alternative technology which captures the use of renewable resources. The motivation for modelling two production technologies is that in many real-world applications, a substitute to an exhaustible resource does require a different production technology or production method. For example, one use of tin is tin-plated steel containers for food packaging and preservation, commonly referred to as tin cans. In 2003, a new type of carton package was developed from coated paperboard, and it has become an important substitute for tin cans. ${ }^{2}$ The production of food containers from paperboard is quite distinct from production of tin cans and requires an entirely different technology. Hence, both capital and labor must be separately allocated to each of the technologies. Similarly, in the case of fossil fuels, production of energy from solar or hydro power requires a production technology which is quite different from production of energy from oil. This model feature is important, because given that production factors are scarce, the decision of how to allocate capital and labor across technologies could play an important role in determining the equilibrium paths of the use of exhaustible as well as renewable resources.

\footnotetext{
${ }^{1}$ Energy Information Administration, www.eia.doe.gov.

${ }^{2}$ The carton package was developed by the company Tetra Pak. For more information, see www.tetrapak.com
} 
The main finding of this paper is that both the time path of extraction and technology adoption do depend on the size of the capital stock in relation to the resource stock, and on the optimal allocation of capital across the two technologies. More specifically, if the capital stock is high in relation to the resource stock, the alternative technology is immediately adopted. The two technologies coexist until the resource is abandoned, and there is a complete switch to the alternative technology. If, instead, the capital stock is low, only the resource technology is used initially and the alternative technology is adopted with a delay. The intuition for this result is that if the resource technology is used it is optimal to allocate capital to that technology first, in order to operate it at a constant resource-capital ratio. If the capital stock is initially low in relation to the resource stock, all capital will be allocated to the resource technology until, over time, capital accumulation yields a sufficiently high level of the capital stock that the alternative technology is adopted. Similarly, the time path of resource extraction depends on the relative sizes of capital and resource stocks. If the capital stock is high in relation to the resource stock, resource extraction is decreasing over time. If, instead, the capital stock is low, resource extraction has the shape of an inverse $\mathrm{U}$; it is first increasing and then decreasing. With a low capital stock, part of the resource extraction is deferred to the future when the capital stock is higher and consequently more capital can be allocated to the resource technology.

The paper also analyzes the effects of industrialization of developing countries on one of our most important exhaustible resources: oil. The term industrialization in this context refers to the process by which developing countries transform their economies to use more advanced technologies and processes which increase output. The model shows that as a result of industrialization of developing countries, the alternative technology for energy production is adopted earlier. This finding is explained by two factors; industrialization tilts the path of oil extraction to the present, and it increases the aggregate capital stock.

There is an extensive literature on exhaustible resources. ${ }^{3}$ One of the first models of optimal extraction of exhaustible resources introducing an alternative to the exhaustible resource, a backstop technology, was formulated by Nordhaus (1973). He described the backstop technology as an ultimate technology using a superabundant resource and capital as inputs. In subsequent articles, several economists have included backstop inputs in models of exhaustible resources. Examples are Dasgupta and Heal (1974), Kamien and Schwartz (1978), and Dasgupta and Stiglitz (1981). In these examples, the backstop input simply delivers a given stream of utility, or is a perfect substitute for the exhaustible resource in production. The models allow for an uncertain arrival of the backstop input. In Dasgupta and Heal (1974) and Dasgupta and Stiglitz (1981), the process is exogenous, while in Kamien and Schwartz (1978), it is determined by investments in R\&D. Nevertheless, as soon as the backstop input has arrived, the exhaustible resource is abandoned. Chakravorty et al. (1997) analyze substitution between different coexisting sources of energy in a partial equilibrium model, and Tahvonen and Salo (2001) develop a general equilibrium model of renewable and nonrenewable energy resources. In the latter model both resources exist from the beginning of time, but in similarity with the studies above, are perfect substitutes in the production function. The authors find that the renewable and the nonrenewable resource will be used simultaneously

\footnotetext{
${ }^{3}$ See Krautkraemer (1998) for an overview.
} 
during a transition period and that the use of nonrenewable resources starts at zero, reaches a maximum, and then approaches zero. Tsur and Zemel (2003) also present a model where the exhaustible resource and the backstop input exist from the beginning of time, and are perfect substitutes. The cost of using the backstop input can be gradually reduced by investment in $R \& D$, and the authors analyze the optimal path of R\&D. Tsur and Zemel (2005) insert this framework into a growth model, and find that the exhaustible resource and the backstop are used simultaneously until the resource is depleted. Just et al. (2005) study technology adoption in a setting with backstop inputs of different quality coupled with uncertainty. They find that the option value of waiting for a better backstop can be sufficiently large that adoption never takes place. Cunha-e-Sá and Reis (2007) analyze the optimal timing of adoption of a cleaner technology. The adoption is modelled as an increase in the productivity of the existing technology. In their model, the optimal timing depends on the marginal utility of environmental quality with respect to consumption.

A large strand of this literature has focused on the relationship between exhaustible resources and long run growth, in an endogenous growth framework. Examples are Bovenberg and Smulders (1995), Bretschger (1998), Aghion and Howitt (1998), Smulders (2000), Grimaud and Rouge (2003), Bretschger and Smulders (2003), Goeschl and Perino (2007), and Groth and Schou (2007). Several of these articles focus on polluting exhaustible resources. Some work has incorporated directed technical change; for example Smulders and de Nooij (2003) and Grimaud and Rouge (2008). For simplicity, the model presented here features no long run growth. However, this analysis focuses on transitions; technology adoption and the effects of industrialization of developing countries.

Most of the models described above (one exception is Tahvonen and Salo (2001)) either assume that resource extraction is costless or model the cost as a function of the extraction rate only. However, the cost of extraction depends on the remaining stock of resource in a given deposit, as well as on the extraction rate. Several factors account for a negative relationship between extraction cost and the remaining stock. As reported by Young (1992), in the case of minerals the most accessible parts of a deposit are extracted first. Depletion of the stock forces the firm to move to less accessible parts, where unfavorable roof and/or floor conditions increase the extraction costs. In the case of oil and gas, the increase in extraction costs stems from a decrease in pressure in the oil or gas field, as the amount of remaining oil or gas decreases. A number of empirical studies have found that extraction costs increase as the remaining stock decreases, for example the works by Pesaran (1990) and Lin (2008) on oil extraction. Halvorsen and Smith (1991) and Young (1992) analyze the metal mining industry and find significant stock effects.

The contribution of this paper is that it analyzes optimal resource use in a general equilibrium model with the following features: two separate production technologies and stock-dependent extraction costs for the exhaustible resource. The former is a feature of many real-world applications of exhaustible resources and substitutes for them, and the latter has been confirmed by extant empirical studies. Both features are important for the equilibrium outcomes. As described above, the results show that the allocation of capital across the two technologies is a determinant of resource extraction paths and technology adoption. Stock-dependent extraction costs affect extraction paths and also allow for a characterization of the point in time when the economy transitions from using a combination of exhaustible and renewable resources 
to relying solely on the latter.

This paper is organized as follows. Section 2 describes the model. Section 3 characterizes the equilibrium in a two-period setting. First, a baseline model is constructed, for which it is possible to derive analytical solutions. The restrictive assumptions of the baseline model are then relaxed in the full model and the implications for technology choice and extraction paths are analyzed. Section 4 extends the model to an infinite time horizon. Section 5 entails an analysis of the effects of industrialization of developing countries on the choice of technology for energy production and on oil extraction. Section 6 concludes.

\section{The Model}

The economy has a stock of capital, denoted $K$, an endowment of labor, denoted $L$, and a stock of an exhaustible natural resource in the ground, denoted $Q$. The resource can be extracted at a flow cost $R(M, Q)$, which is a function of the remaining stock of resource and the extraction rate, denoted $M$. There is no growth in the labor force. The economy has two technologies available for production of output. First, a resource technology, denoted $F(M, K, L)$, which uses the exhaustible resource, capital and labor as inputs and second, an alternative technology, denoted $G(K, L)$, which has capital and labor as inputs. The resource technology has the following functional form

$$
F(M, K, L)=B\left(\left(K-K_{A}\right)^{\theta}\left(L-L_{A}\right)^{1-\theta}\right)^{\alpha_{1}} M^{\alpha_{2}}
$$

where $K_{A}$ is the amount of capital allocated to the alternative technology and $L_{A}$ is the amount of labor allocated to the alternative technology. $B>0, \alpha_{1} \in(0,1), \alpha_{2} \in(0,1)$ and $\theta \in(0,1)$. The alternative technology has the following functional form

$$
G(K, L)=A K_{A}^{\theta} L_{A}^{1-\theta}
$$

where $A>0 .^{4}$ Implicit in this formulation are the assumptions that capital is not technology-specific and that capital and labor are used in the same proportions in both technologies. Both assumptions are made for simplicity. However, as a robustness check, I relax the latter assumption in Section 5 and the main results are robust to this change. The flow cost of resource extraction, $R(M, Q)$, has the following functional form

$$
R(M, Q)=C\left(Q^{1-\sigma}-(Q-M)^{1-\sigma}\right)
$$

where $C>0$ and $\sigma \in(0,1)$. The cost function has the following properties: $R_{M}(M, Q)>0, R_{M M}(M, Q)>$ $0, R_{Q}(M, Q)<0$ and $R_{Q Q}(M, Q)>0$. The cost of extraction increases as the stock of resource decreases, and the incremental cost due to stock effects rises with the depletion of the stock. In addition, it is assumed that the cost of extracting the very last amount of a resource is prohibitively high, which follows from the specification of the extraction cost function:

$$
\lim _{M \rightarrow Q} \frac{\partial R(M, Q)}{\partial M} \rightarrow \infty .
$$

\footnotetext{
${ }^{4}$ To make the problem interesting, the productivity of the alternative technology, $A$, must be such that if the resource is abundant, the resource technology is used.
} 
The economy has one representative consumer, whose utility function is $U(c)$, where $c$ denotes consumption. The model is solved for the centralized equilibrium. Given initial conditions $K_{0}$ and $Q_{0}$, the social planner faces the following optimization problem

$$
\begin{aligned}
& \quad \max _{\left\{M_{t}, K_{A, t}, L_{A, t}, K_{t+1}\right\}_{t=0}^{\infty}} \sum_{t=0}^{\infty} \beta^{t} U\left(c_{t}\right) \\
& \text { s.t. } \\
& Q_{t+1}=Q_{t}-M_{t} \\
& c_{t}=A K_{A, t}^{\theta} L_{A, t}^{1-\theta}+B\left(\left(K_{t}-K_{A, t}\right)^{\theta}\left(L-L_{A, t}\right)^{1-\theta}\right)^{\alpha_{1}} M_{t}^{\alpha_{2}} \\
& \quad-C\left(Q_{t}^{1-\sigma}-\left(Q_{t}-M_{t}\right)^{1-\sigma}\right)-K_{t+1} \\
& 0 \leq M_{t} \leq Q_{t}, 0 \leq K_{A, t} \leq K_{t}, 0 \leq L_{A, t} \leq L \\
& c_{t} \geq 0 \\
& \forall t .
\end{aligned}
$$

In each time period $t$, the social planner chooses extraction rate $M_{t}$, the amount of capital allocated to the alternative technology $K_{A, t}$, the amount of labor allocated to the alternative technology $L_{A, t}$, and the aggregate capital stock to enter next period $K_{t+1}$, so as to maximize the utility of the representative consumer. Savings are chosen in terms of the aggregate capital stock and in the subsequent time period, the social planner determines its division between the two technologies. There is a borrowing constraint, such that savings cannot exceed output.

The model does not incorporate emissions of carbon dioxide, an important consequence of the use of a category of exhaustible resources; fossil fuels. Modelling emissions of carbon dioxide and the effects of climate change is computationally complicated and for purely computational reasons, emissions of carbon dioxide are not included in the model. However, I argue that the model can still give important insights into the optimal extraction of exhaustible resources in general, and into the effects of industrialization of developing countries on extraction of fossil fuels. The first part of the analysis describes the optimal paths of resource extraction and technology choice over time and pertains to all exhaustible resources; for example copper, zinc, aluminum, tin etc. In these cases, there is no need to consider emissions of carbon dioxide. When it comes to fossil fuels, the equilibrium outcomes in this first part of the analysis should be seen as a benchmark result against which we can compare the outcomes when measures are taken to reduce emissions of carbon dioxide on a global scale. The second part of the analysis in this paper considers the effects of industrialization of developing countries on the time path of resource extraction and on technology choice. The model is calibrated for oil and therefore climate change considerations should affect oil extraction. However, in this case the model is used to analyze changes: namely how oil extraction and adoption of alternative technologies change qualitatively with industrialization. Therefore, I argue that as long as climate change considerations are stable, the main results from this analysis would not be affected by taking global warming into account. I will return to the effects of this simplification of the model in Section 5 . 


\section{Two time periods}

To illustrate the factors affecting the optimal choices of extraction rate and technology, the optimization problem is first cast in a two-period setting and thereafter time is extended to an infinite horizon. In a two-period setting, the optimization problem in (5) is

$$
\begin{aligned}
& \quad \max _{\left\{M_{t}, K_{A, t}, L_{A, t}, K_{t+1}\right\}_{t=1}^{2}} U\left(c_{1}\right)+\beta U\left(c_{2}\right) \\
& \text { s.t. } \\
& \begin{aligned}
& Q_{2}= Q_{1}-M_{1} \\
& c_{1}= A K_{A, 1}^{\theta} L_{A, 1}^{1-\theta}+B\left(\left(K_{1}-K_{A, 1}\right)^{\theta}\left(L-L_{A, 1}\right)^{1-\theta}\right)^{\alpha_{1}} M_{1}^{\alpha_{2}} \\
& \quad-C\left(Q_{1}^{1-\sigma}-\left(Q_{1}-M_{1}\right)^{1-\sigma}\right)-K_{2} \\
& c_{2}= A K_{A, 2}^{\theta} L_{A, 2}^{1-\theta}+B\left(\left(K_{2}-K_{A, 2}\right)^{\theta}\left(L-L_{A, 2}\right)^{1-\theta}\right)^{\alpha_{1}} M_{2}^{\alpha_{2}} \\
& \quad-C\left(Q_{2}^{1-\sigma}-\left(Q_{2}-M_{2}\right)^{1-\sigma}\right) \\
& 0 \leq M_{1} \leq Q_{1}, 0 \leq K_{A, 1} \leq K_{1}, 0 \leq L_{A, 1} \leq L \\
& 0 \leq M_{2} \leq Q_{2}, 0 \leq K_{A, 2} \leq K_{2}, 0 \leq L_{A, 2} \leq L \\
& c_{1}, c_{2} \geq 0
\end{aligned}
\end{aligned}
$$

The optimal allocations are now described in turn, starting with the interior solutions.

\subsection{Interior solutions}

In an interior solution in period $2, M_{2}^{*} \in\left(0, Q_{2}\right), K_{A, 2}^{*} \in\left(0, K_{2}\right)$, and $L_{A, 2}^{*} \in(0, L)$ satisfy the following system of equations

$$
\begin{aligned}
& \alpha_{2} B\left(\left(K_{2}-K_{A, 2}\right)^{\theta}\left(L-L_{A, 2}\right)^{1-\theta}\right)^{\alpha_{1}} M_{2}^{\alpha_{2}-1}=(1-\sigma) C\left(Q_{2}-M_{2}\right)^{-\sigma} \\
& A K_{A, 2}^{\theta-1} L_{A, 2}^{1-\theta}=\alpha_{1} B\left(K_{2}-K_{A, 2}\right)^{\theta \alpha_{1}-1}\left(L-L_{A, 2}\right)^{(1-\theta) \alpha_{1}} M_{2}^{\alpha_{2}} \\
& A K_{A, 2}^{\theta} L_{A, 2}^{-\theta}=\alpha_{1} B\left(K_{2}-K_{A, 2}\right)^{\theta \alpha_{1}}\left(L-L_{A, 2}\right)^{(1-\theta) \alpha_{1}-1} M_{2}^{\alpha_{2}} .
\end{aligned}
$$

Equations (7), (8) and (9) are conditions for production efficiency. In (7), the marginal product of the resource is equalized to the marginal cost of extracting the resource. The equations in (8) and (9) equalize the marginal product of capital and labor, respectively, across the two technologies.

In an interior solution in period $1, M_{1}^{*} \in\left(0, Q_{1}\right), K_{A, 1}^{*} \in\left(0, K_{1}\right)$, and $L_{A, 1}^{*} \in(0, L)$ satisfy the following system of equations

$$
\begin{gathered}
U^{\prime}\left(c_{1}\right)\left(\alpha_{2} B\left(\left(K_{1}-K_{A, 1}\right)^{\theta}\left(L-L_{A, 1}\right)^{1-\theta}\right)^{\alpha_{1}} M_{1}^{\alpha_{2}-1}-(1-\sigma) C\left(Q_{1}-M_{1}\right)^{-\sigma}\right) \\
=\beta U^{\prime}\left(c_{2}\right) C(1-\sigma)\left(\left(Q_{1}-M_{1}-M_{2}\right)^{-\sigma}-\left(Q_{1}-M_{1}\right)^{-\sigma}\right) \\
A K_{A, 1}^{\theta-1} L_{A, 1}^{1-\theta}=\alpha_{1} B\left(K_{1}-K_{A, 1}\right)^{\theta \alpha_{1}-1}\left(L-L_{A, 1}\right)^{(1-\theta) \alpha_{1}} M_{1}^{\alpha_{2}} \\
A K_{A, 1}^{\theta} L_{A, 1}^{-\theta}=\alpha_{1} B\left(K_{1}-K_{A, 1}\right)^{\theta \alpha_{1}}\left(L-L_{A, 1}\right)^{(1-\theta) \alpha_{1}-1} M_{1}^{\alpha_{2}} .
\end{gathered}
$$


The equation in (10) determines the optimal allocation of resource extraction across the two periods. The first term on the left-hand side is the marginal product of the resource, weighed by the marginal utility of consumption in period 1 . The second term is the marginal cost of extracting the resource in period 1, weighed by marginal utility of consumption in period 1 . The term on the right-hand side is the marginal value of not extracting in period 1, which yields a higher resource stock entering period 2 and hence a lower marginal extraction cost in that period. This value is weighed by the marginal utility of consumption in period 2. The effect of stock-dependent extraction costs on the optimal time path of resource extraction can easily be seen from this equation; the extraction rate in period $1, M_{1}$, directly affects the cost of extraction in the second period as the decrease in resource stock makes future extraction more costly. Equations (11) and (12) ensure production efficiency within the period by equalizing the marginal products of capital and labor, respectively, across the two technologies.

\subsection{Corner solutions}

The functional form of $R(M, Q)$ restricts the corner solutions as follows. As seen from $(4), M^{*}<Q$. Hence, it is never optimal to extract the entire resource stock. However, extraction can be zero. If it is optimal to set resource extraction to zero, it will also be optimal to allocate all capital and labor to the alternative technology. Hence, the allocation $M_{t}^{*}=0, K_{A, t}^{*}=K_{t}$, and $L_{A, t}^{*}=L$ is a possible corner solution. The intuition for the optimality of this corner solution is that with stock-dependent extraction costs for the resource, even extracting a very small amount can be very costly if the remaining stock is low. The other possible corner solution arises if the alternative technology is not used at all; $K_{A, t}^{*}=0$ and $L_{A, t}^{*}=0$. Let the optimal extraction in this case be denoted $M_{c, t}$, where subscript $c$ indicates the corner solution. In $t=1, M_{c, t}$ is given by (10), with $K_{A, 1}=0$ and $L_{A, 1}=0$. In $t=2, M_{c, t}$ is given by (7) with $K_{A, 2}=0$ and $L_{A, 2}=0$. The intuition for the optimality of this corner solution is the following. If the resource stock is high, extraction costs are low and it is optimal to extract large quantities of the resource. In order to optimize the resource production technology, the social planner may want to allocate large quantities of capital and labor to it, such that the entire capital stock is allocated to the resource technology and the alternative technology is not used. Each of the two corner solutions can arise in each time period. To obtain more precise predictions for the technology choices made across the two time periods, additional assumptions are needed.

\subsection{Saving}

Saving in period 1 is determined by the following equation

$$
\begin{aligned}
& U^{\prime}\left(c_{1}\right)=\beta \theta \alpha_{1} B\left(K_{2}-K_{A, 2}\right)^{\theta \alpha_{1}-1}\left(L-L_{A, 2}\right)^{(1-\theta) \alpha_{1}} M_{2}^{\alpha_{2}} U^{\prime}\left(c_{2}\right) \\
& \text { s.t. } \\
& \quad K_{2} \leq A K_{A, 1}^{\theta} L_{A, 1}^{1-\theta}+B\left(\left(K_{1}-K_{A, 1}\right)^{\theta}\left(L-L_{A, 1}\right)^{1-\theta}\right)^{\alpha_{1}} M_{1}^{\alpha_{2}} \\
& \quad-C\left(Q_{1}^{1-\sigma}-\left(Q_{1}-M_{1}\right)^{1-\sigma}\right) .
\end{aligned}
$$




\subsection{A baseline model}

For the purpose of deriving analytical solutions for the technology choices in the two-period setting, I construct a very simplistic baseline model. The baseline model is one where the following holds: there is no labor, the utility function is linear in consumption, and the discount factor is equal to 1 . More formally, it is assumed that the production functions are

$$
\begin{aligned}
F(M, K) & =B\left(K-K_{A}\right)^{\alpha_{1}} M^{\alpha_{2}} \\
G(K) & =A K_{A},
\end{aligned}
$$

and in addition, $U\left(c_{t}\right)=c_{t}$, and $\beta=1$. Given the linear utility function, the parameter restriction $\beta A=1$ is imposed. Each of these assumptions will be relaxed subsequently.

\subsubsection{Interior solutions}

In an interior solution in period $2, M_{2}^{*} \in\left(0, Q_{2}\right)$ and $K_{A, 2}^{*} \in\left(0, K_{2}\right)$ satisfy the following system of equations

$$
\begin{aligned}
\alpha_{2} B\left(K_{2}-K_{A, 2}\right)^{\alpha_{1}} M_{2}^{\alpha_{2}-1} & =(1-\sigma) C\left(Q_{2}-M_{2}\right)^{-\sigma} \\
A & =\alpha_{1} B\left(K_{2}-K_{A, 2}\right)^{\alpha_{1}-1} M_{2}^{\alpha_{2}} .
\end{aligned}
$$

As can be seen from (16), the marginal product of capital is constant in the alternative technology. In the resource technology, the marginal product is varying with the amount of resource input $M$. Under constant returns to scale in the resource technology, an interior solution implies that the ratio of resource to capital in the resource technology is

$$
\frac{M_{2}}{K_{2}-K_{A, 2}}=\left(\frac{A}{\alpha_{1} B}\right)^{\frac{1}{1-\alpha_{1}}}
$$

The expression in (17) shows that it is optimal to produce using resource and capital in fixed proportions, irrespective of the level of resource input. This implies that if the resource technology is used, it will be optimal to first allocate capital to the resource technology in fixed proportion to the resource and then allocate the remaining capital to the alternative technology. The resource-capital ratio is determined by the relative productivities of the two technologies. An increase in $B$ decreases the resource-capital ratio, as more capital is allocated to the resource technology, for a given amount of resource input. Conversely, an increase in $A$ increases the resource-capital ratio, as more capital is allocated to the alternative technology.

In an interior solution in period $1, M_{1}^{*} \in\left(0, Q_{1}\right)$ and $K_{A, 1}^{*} \in\left(0, K_{1}\right)$ satisfy the following system of equations

$$
\begin{aligned}
& \alpha_{2} B\left(K_{1}-K_{A, 1}\right)^{\alpha_{1}} M_{1}^{\alpha_{2}-1}-(1-\sigma) C\left(Q_{1}-M_{1}\right)^{-\sigma} \\
& =\beta C(1-\sigma)\left(\left(Q_{1}-M_{1}-M_{2}\right)^{-\sigma}-\left(Q_{1}-M_{1}\right)^{-\sigma}\right) \\
& A=\alpha_{1} B\left(K_{1}-K_{A, 1}\right)^{\alpha_{1}-1} M_{1}^{\alpha_{2}} .
\end{aligned}
$$

It can be shown that the economy exhibits constant returns to scale. For details, see Appendix A1. 


\subsubsection{Corner solutions}

In the baseline model, it is possible to solve analytically for the conditions under which the corner solutions arise. Starting with the corner solution $M_{t}^{*}=0$, and $K_{A, t}^{*}=K_{t}$ the following holds.

Proposition 1 If $\alpha_{1}+\alpha_{2}=1$, there exists a $\hat{Q}>0$ such that for $Q \leq \hat{Q}, M^{*}=0$, where

$$
\hat{Q}=\frac{A^{\frac{\alpha_{1}}{\sigma\left(1-\alpha_{1}\right)}} C^{\frac{1}{\sigma}}(1-\sigma)^{\frac{1}{\sigma}}}{\alpha_{2}^{\frac{1}{\sigma}} B^{\frac{1}{\sigma\left(1-\alpha_{1}\right)}} \alpha_{1}^{\frac{\alpha_{1}}{\sigma\left(1-\alpha_{1}\right)}}} .
$$

Proof. See Appendix A2.

Provided that the resource technology exhibits constant returns to scale, it will be optimal to refrain from extracting the resource at all if the resource stock is sufficiently low. Hence, the model shows that the resource stock will not be physically depleted, it will be abandoned when it is no longer economically viable to extract from it. The threshold value $\hat{Q}$ is increasing in $A$ as higher productivity of the alternative technology makes it optimal to abandon the resource with more left in the ground. It is decreasing in $B$, as higher productivity of the resource technology makes it optimal to extract more before the resource is abandoned. It is increasing in $C$ and decreasing in $\sigma$, as higher costs of extraction make it optimal to abandon the resource with more left in the ground.

The second corner solution has $K_{A, t}^{*}=0$ and $M_{t}^{*}=M_{c, t}$. In $t=1, M_{c, t}$ is given by (18) with $K_{A, 1}=0$, and in $t=2$ by (15) with $K_{A, 2}=0$. Under constant returns to scale in the resource technology, there is a threshold value $\tilde{M}$ such that for $M_{t} \geq \tilde{M}, K_{A, t}^{*}=0$, where

$$
\tilde{M}=K\left(\frac{A}{\alpha_{1} B}\right)^{\frac{1}{\alpha_{2}}} \text {. }
$$

The threshold can be reformulated in terms of the capital stock; $K_{A, t}^{*}=0$, if $K_{t} \leq \hat{K}\left(Q_{t}\right)$, where

$$
\hat{K}(Q)=\left(\frac{\alpha_{1} B}{A}\right)^{\frac{1}{\alpha_{2}}}(Q-\hat{Q}) .
$$

If the capital stock is sufficiently low in relation to the resource stock, all capital is allocated to the resource technology. As described earlier, if the resource technology is used, it is optimal to first allocate available capital to the resource technology, and such that the resource-capital ratio is constant. The threshold $\hat{K}(Q)$ is increasing in $Q$, as a higher resource stock implies a higher total extraction and hence, a higher capital stock is required. It is possible to derive conditions under which there is an analytical solution for the total amount of resource extracted over the two periods.

Proposition 2 If a pair $\left(Q_{2}, K_{2}\right)$ is such that $K_{2}>\hat{K}\left(Q_{2}\right)$, then $M_{1}^{*}+M_{2}^{*}=M^{T}$,

where

$M^{T}=Q_{1}-\hat{Q}$.

Proof. See Appendix A2. 
Total extraction is equal to $M^{T}$ as long as the alternative technology is used at least in period 2 . The intuition for this result is the following. As long as there is enough capital in at least one of the periods to enable the resource technology to be operated at the optimal resource-capital ratio, extraction will continue until it becomes optimal to abandon the resource, which occurs at $\hat{Q}$.

\subsubsection{Saving}

Saving in period 1 is determined by

$$
\begin{aligned}
& 1=\beta \alpha_{1} B\left(K_{2}-K_{A, 2}\right)^{\alpha_{1}-1} M_{2}^{\alpha_{2}} \\
& \text { s.t. } \\
& K_{2} \leq A K_{A, 1}+B\left(K_{1}-K_{A, 1}\right)^{\alpha_{1}} M_{1}^{\alpha_{2}}-C\left(Q_{1}^{1-\sigma}-\left(Q_{1}-M_{1}\right)^{1-\sigma}\right) .
\end{aligned}
$$

Under the parameter restriction $\beta A=1$, the expressions for $K_{2}$ given by the above equation and (16) are identical. Hence, the amount of capital allocated to the resource technology can be determined, but not $K_{2}$. Consequently, the social planner will be indifferent over initial capital stocks in period 2, as long as the capital stocks are sufficient to enable production with the resource technology at the optimal resource-capital ratio. If the initial capital stock in period 1 is low in relation to the resource stock, it will be optimal to save. The borrowing constraint implies that for some initial conditions, the amount of savings will be constrained. In this case, the social planner will not be indifferent over $K_{2}$; the maximum feasible value of $K_{2}$ yields strictly higher utility than any lower value. Hence, if the borrowing constraint binds, the optimal amount of savings is determined, whereas if it does not, savings are indeterminate.

\subsubsection{Technology choice}

As discussed previously, several technology combinations can occur in the two-period setting. In the simple baseline model, it is possible to distinguish between four cases. Each case will now be discussed in turn.

\subsubsection{Case 1}

In case 1 , there is no extraction of the resource in either period. This case arises if $Q_{1} \leq \hat{Q}$. Naturally, it follows that $Q_{2} \leq \hat{Q}$. The allocations are $M_{1}^{*}=0, K_{A, 1}^{*}=K_{1}, M_{2}^{*}=0$, and $K_{A, 2}^{*}=K_{2}$.

\subsubsection{Case 2}

In case 2, the alternative technology is used in both periods and there is positive resource extraction. Total extraction over both periods is equal to $M^{T}$, as defined in Proposition 2. The division of $M^{T}$ into $M_{1}$ and $M_{2}$ cannot be determined; hence there are multiple solutions for $M_{1}$ and $M_{2}$. The allocations are $K_{A, 1}^{*}>0, K_{A, 2}^{*}>0, M_{1}^{*} \in\left[0, M^{T}\right]$, and $M_{2}^{*} \in\left[0, M^{T}\right]$. The conditions under which case 2 arises are the following.

Proposition 3 Case 2 arises if a pair $\left(K_{1}, Q_{1}\right)$ is such that $Q_{1}>\hat{Q}$ and $K_{1}>\hat{K}\left(Q_{1}\right)$. 
Proof. See Appendix A2.

If the initial value of the capital stock is sufficiently high in relation to the resource stock, it follows that the alternative technology is always used in both periods and the social planner is indifferent between the following extraction paths. First, the extraction of $M^{T}$ in period 1 and zero in period 2, second, the extraction of zero in period 1 and $M^{T}$ in period 2 and third, any division of total extraction $M^{T}$ such that extraction is positive in both periods. Hence, it is possible that the resource technology is used in the first period only, the second period only, or in both periods, while the alternative technology is always used in both periods. The indifference is due to the functional form for the cost of resource extraction. The extraction rate affects the extraction costs through its effect on the remaining resource stock and given linear utility and no discounting, this effect is constant across the two periods.

\subsubsection{Case 3}

In case 3 , the resource technology is used in both periods and consequently extraction is positive in both periods; $M_{1}^{*}>0$, and $M_{2}^{*}>0$. However, the economy may use the alternative technology in both periods or in either of the time periods; $K_{A, 1}^{*}>0$ and $K_{A, 2}^{*}>0$, or $K_{A, 1}^{*}>0$ and $K_{A, 2}^{*}=0$, or $K_{A, 1}^{*}=0$ and $K_{A, 2}^{*}>0$. Using the threshold $\tilde{M}$, it is possible to define the conditions under which case 3 arises as follows.

Proposition 4 Case 3 arises if a pair $\left(Q_{1}, K_{1}\right)$ is such that $Q_{1}>\hat{Q}, K_{1} \leq \hat{K}\left(Q_{1}\right)$, and $K_{2}>\hat{K}\left(Q_{2}\right)$, where

$$
\begin{aligned}
& Q_{2}=Q_{1}-\tilde{M}, \text { and } \\
& K_{2}=\frac{A K_{1}}{\alpha_{1}}-C\left(Q_{1}^{1-\sigma}-\left(Q_{1}-\tilde{M}\right)^{1-\sigma}\right) .
\end{aligned}
$$

Proof. See Appendix A2.

If the capital stock is slightly lower in relation to the resource stock, case 3 arises. The resource technology is used in both periods. The consumer is indifferent over producing with the alternative technology in the first period only, producing with the alternative technology in the second period only, or producing with the alternative technology in both periods. As in case 2, the indifference is due to the functional form for extraction costs, in combination with linear utility and no discounting.

\subsubsection{Case 4}

In case 4, the alternative technology is never adopted, while the resource technology is used both periods. The allocations are $K_{A, 1}^{*}=K_{A, 2}^{*}=0, M_{1}^{*}>0$, and $M_{2}^{*}>0$. Again, with the use of $\tilde{M}$, the conditions under which case 4 arises can be stated as follows.

Proposition 5 Case 4 arises if a pair $\left(Q_{1}, K_{1}\right)$ is such that $Q_{1}>\hat{Q}, K_{1} \leq \hat{K}\left(Q_{1}\right)$, and $K_{2} \leq \hat{K}\left(Q_{2}\right)$, where

$Q_{2}=Q_{1}-\tilde{M}$, and 


$$
K_{2}=\frac{A K_{1}}{\alpha_{1}}-C\left(Q_{1}^{1-\sigma}-\left(Q_{1}-\tilde{M}\right)^{1-\sigma}\right) .
$$

Proof. See Appendix A2.

If the initial capital stock is sufficiently low in relation to the resource stock that even after saving, the alternative technology is not adopted in period 2, then case 4 arises.

\subsubsection{Numerical example}

To illustrate the four cases described above, the model is solved numerically. The parameterization is as follows. Suppose that the exhaustible resource is fossil fuels. Nordhaus (1992) argues that the share of energy to GDP is roughly 10 percent and therefore I set $\alpha_{1}=0.9$ and $\alpha_{2}=0.1$. As regards the extraction cost function, due to the lack of empirical estimations of $\sigma$, it is set to an intermediate value; $\sigma=0.5$. Parameters $B$ and $C$ scale the functions $F(M, K)$ and $R(M, Q)$ and are chosen so as to ensure that all four cases of technology choice arise within the interval $K_{1} \in[0,6]$ and $Q_{1} \in[0,6]$. Given $A=1$, this implies that $B=1.12$ and $C=0.15$. Varying these parameters does not affect the characteristics of the four cases, but the length of vectors $K_{1} \in\left[K^{\min }, K^{\max }\right]$ and $Q_{1} \in\left[Q^{\min }, Q^{\max }\right]$ for which all cases are represented. Figure 1 depicts the technology choices made across both time periods given initial conditions $K_{1}$ and $Q_{1}$.

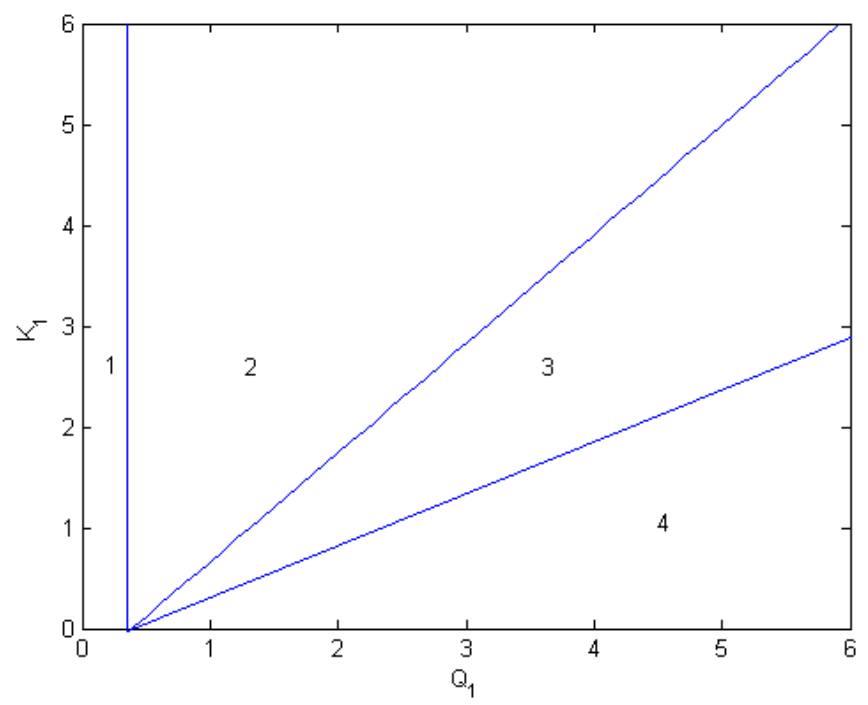

Figure 1. Technology choice in the baseline model.

In the figure, area 1 corresponds to case 1 , area 2 to case 2 , and so forth. The vertical line represents threshold $\hat{Q}$. The line separating areas 2 and 3 is given by threshold $\hat{K}\left(Q_{1}\right)$ and the line separating areas 3 and 4 is given by threshold $\hat{K}\left(Q_{2}\right)$. As seen in the figure, case 1 arises if the initial resource stock is 
low. Case 2 arises if the initial capital stock is high in relation to the initial resource stock. Case 3 arises if the initial capital stock is lower and finally, case 4 arises if the initial capital stock is even lower.

Figure 1 can illustrate some comparative statics with respect to technology choice. First, consider an increase in $A$, the productivity of the alternative technology. An increase in $A$ shifts threshold $\hat{Q}$ to the right and threshold $\hat{K}\left(Q_{1}\right)$ downwards while the effect on $\hat{K}\left(Q_{2}\right)$ is ambiguous. When the alternative technology has a higher productivity, it is used in both periods for a larger set of initial conditions and the resource will be abandoned for a larger set of initial conditions. Second, consider an increase in $B$, the productivity of the resource technology. An increase in $B$ shifts $\hat{Q}$ to the left and $\hat{K}\left(Q_{1}\right)$ upwards while the effect on $\hat{K}\left(Q_{2}\right)$ is ambiguous. If the productivity of the resource technology increases, the alternative technology is used in both periods for a smaller set of initial conditions. Similarly, the resource is abandoned for a smaller set of initial conditions. Third, if the cost of resource extraction increases, either by an increase in $C$ or a decrease in $\sigma, \hat{Q}$ shifts to the right and $\hat{K}\left(Q_{1}\right)$ shifts downwards, while the effect on $\hat{K}\left(Q_{2}\right)$ is ambiguous. An increase in extraction costs implies that the alternative technology will be used in both periods for a larger set of initial conditions and the resource abandoned for a larger set of initial conditions.

In the baseline model, it is possible to characterize the technology choices made for all combinations of initial conditions $Q_{1}$ and $K_{1}$. The technology choice belongs to one of four possible cases and is determined by the relative sizes of the capital stock and the resource stock. It is also possible to analyze how parameters of the production functions and the extraction cost function affect technology choice. However, the model entails several assumptions which, while enabling analytical solutions, are quite restrictive. Therefore, these assumptions will be relaxed and labor reintroduced into the model. The next step is to investigate whether the characterizations of technology choice derived in the baseline model also hold true in the full model. In the following analysis, it will be necessary to resort to numerical solutions.

\subsection{The model with log utility and labor}

Now, the assumptions of the baseline model are relaxed. The consumer has the following utility function: $U\left(c_{t}\right)=\log \left(c_{t}\right)$ and values the future less than the present; $\beta<1$. In addition, labor is reintroduced into both production functions, as given by equations (1) and (2). The model is solved numerically using the same parameterization as in the baseline model; $\alpha_{1}=0.9, \alpha_{2}=0.1, \sigma=0.5, B=1.12, C=0.15$, and $A=1$. Nordhaus (1992) uses a labor income share of 0.6 and this paper follows his example. The parameter $\theta$ is set to $=0.33$, which yields a capital income share of 0.3 and a labor income share of 0.6 for the resource technology. Following Nordhaus and Yang (1996), the yearly discount rate is 3 percent. One time period is 10 years, which gives $\beta=0.74$. The supply of labor is set to $L=16$.

The more realistic assumptions regarding preferences imply that the consumer wishes to smooth consumption and therefore, $K_{2}$ is uniquely determined. In addition, the consumer is no longer indifferent over in what time period extraction takes place. As a consequence, the technology choices in cases 2 and 3 can be more precisely described. In case 2 , the alternative technology is used in both periods and the resource is extracted in period 1 and possibly in period 2 as well. In case 3, the alternative technology 
is not adopted in the first period, but in the second. Let case 2 be denoted the immediate-adoption case and case 3 be denoted the late-adoption case. The allocations and time paths arising in the immediateadoption case and the late-adoption case are illustrated by numerical examples. Figure 2 depicts the time path for the example of the immediate-adoption case, with $K_{1}=1$ and $Q_{1}=1$.
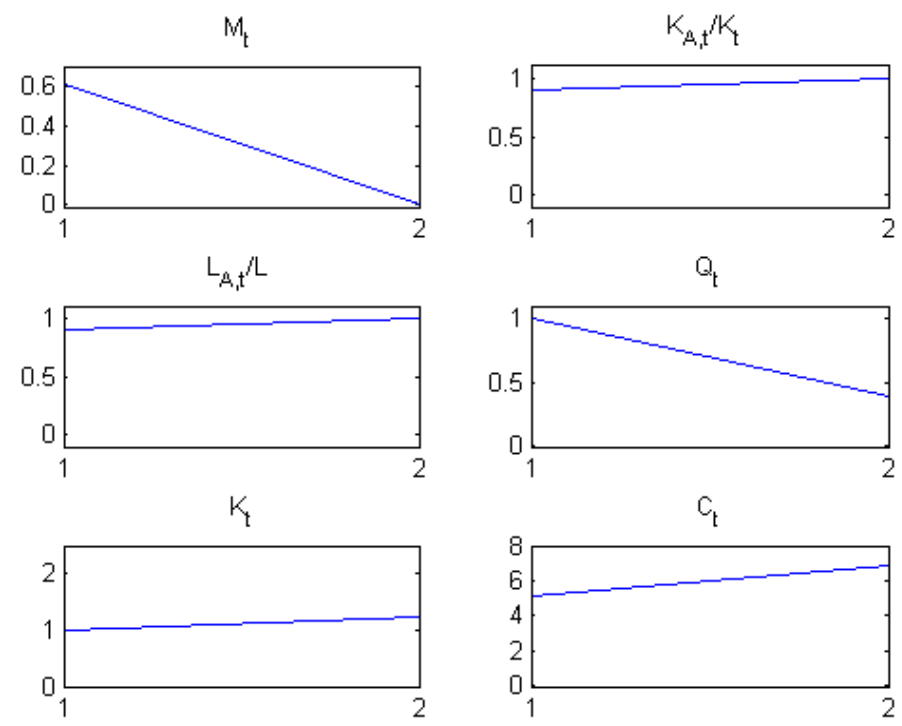

Figure 2. Example of the immediate-adoption case.

In this case, the initial capital stock is sufficiently high in relation to the resource stock for the alternative technology to be adopted in the first period. As seen in Figure 2, almost the entire total resource extraction takes place in the first period.

Figure 3 depicts the time path for the example of the late-adoption case, with $K_{1}=1$ and $Q_{1}=8$. In the late-adoption case, all capital in period 1 is allocated to the resource technology. The initial capital stock is not sufficiently high for the alternative technology to be adopted immediately, but it is adopted in period 2. The low initial capital stock implies that a higher share of the total resource extraction is deferred to period 2 . 

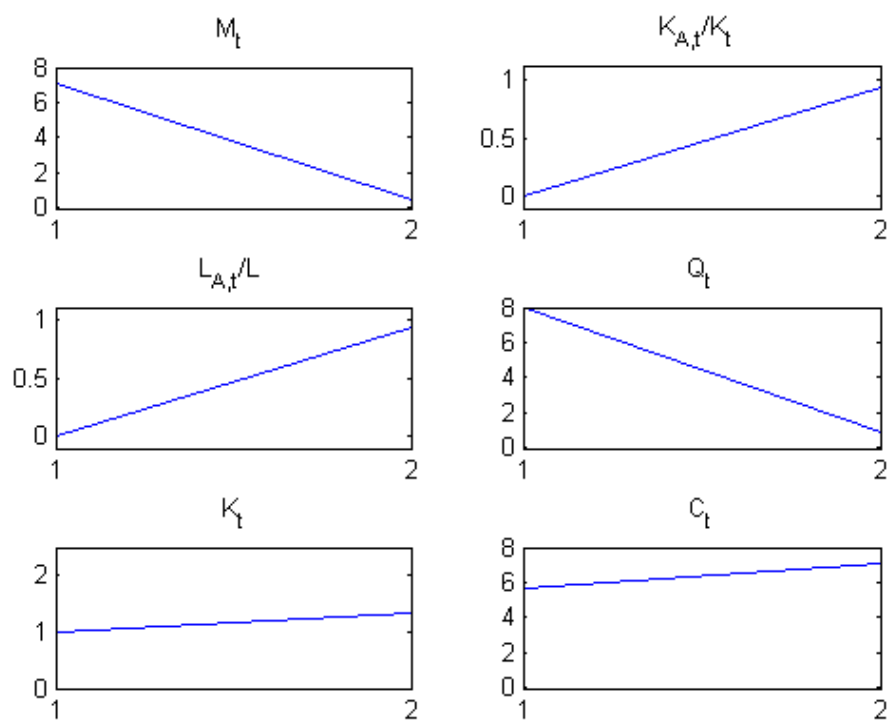

Figure 3. Example of the delayed-adoption case.

In sum, introducing more realistic preferences as well as labor into the model implies that there are still four cases of technology choice to consider. The two most interesting of these cases are the immediateadoption case and the late-adoption case. Although the conditions under which each case arises cannot be explicitly derived, the main features of this version of the model are as those in the baseline model. The immediate-adoption case arises if the initial capital stock is high in relation to the resource stock, while the late-adoption case arises if the initial capital stock is relatively low in relation to the resource stock. This result can be compared to the analysis by Cunha-e-Sá and Reis (2007). In their model of technology adoption, the optimal adoption of a green technology depends on the capital stock. However, that model has a different mechanism; adoption depends on the marginal utility of environmental quality with respect to consumption, and the capital stock affects consumption.

\section{Infinite time horizon}

This section analyzes the properties of the full model when time is extended to an infinite horizon. As will be shown below, there is one main effect of extending the number of time periods, namely that irrespective of initial conditions, the economy will eventually adopt the alternative technology and the resource will be abandoned. Which case arises initially is determined by the same conditions as in the two-period model, namely the relative sizes of the capital stock and the resource stock. However, the time path of resource extraction can now be increasing. In the numerical solution of the infinite horizon model, the 
parameterization is as follows; $\alpha_{1}=0.9, \alpha_{2}=0.1, \theta=0.33, \sigma=0.5, \beta=0.74, L=16$, and $A=1.35 .^{5}$ For details on the solution method, see Appendix A3. The time paths for the economy for examples of different initial conditions $K_{0}$ and $Q_{0}$ are shown in Figures 4-6. The figures display the time paths for 10 periods, which is equal to one hundred years.

Figure 4 depicts the time path for the economy for $K_{0}=3$ and $Q_{0}=3.2$. A high initial capital stock relative to the resource stock implies that the time path of extraction is downward-sloping over the entire time period. The alternative technology is immediately adopted and the resource is abandoned in period 2 .
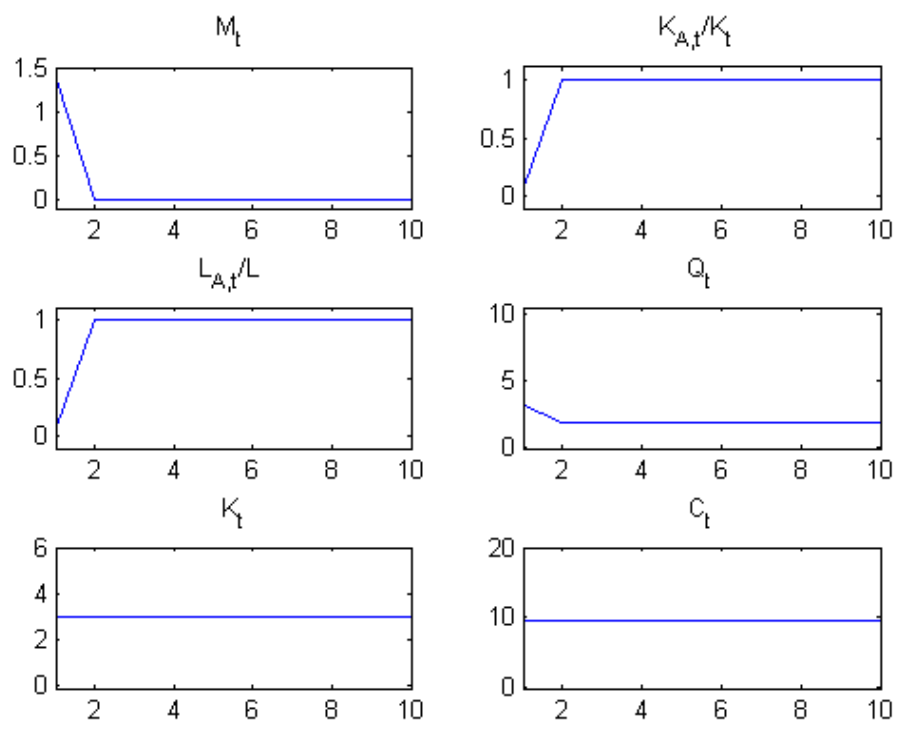

Figure 4. Time paths for initial conditions $K_{0}=3$ and $Q_{0}=3.2$.

\footnotetext{
${ }^{5}$ As described above, parameters $B=1.8$ and $C=2.5$ are chosen so as to ensure that the different cases of technology choice arise within the chosen grid for $K$ and $Q$.
} 
Figure 5 depicts the time path for the economy for $K_{0}=1.5$ and $Q_{0}=7$. A lower initial capital stock implies that the time path of resource extraction is initially flat and then downward-sloping. The alternative technology is not adopted until period 4 and the resource is abandoned in period 5 .
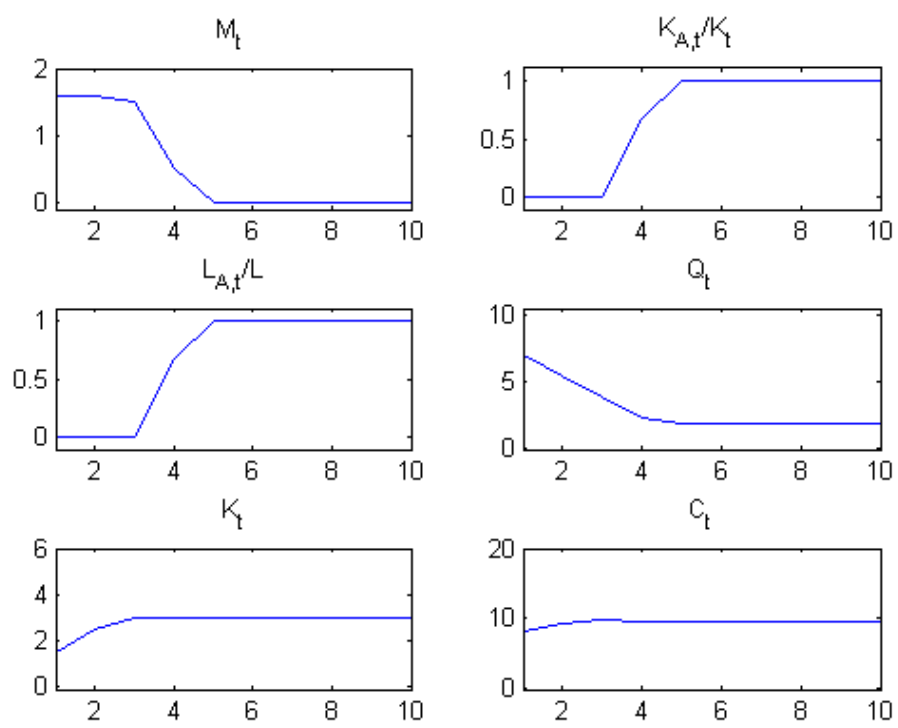

Figure 5. Time paths for initial conditions $K_{0}=1.5$ and $Q_{0}=7$.

Figure 6 depicts the time path for $K_{0}=0.5$ and $Q_{0}=9$. A substantially lower initial capital stock relative to the resource stock implies that the time path of resource extraction is increasing for the first 3 periods and then decreasing. In addition, the time path of the capital stock is increasing for the first 4 periods, as capital is accumulated. The alternative technology is not adopted until period 5. The initial increase in resource extraction occurs while the capital stock is sufficiently low that no capital is allocated to the alternative technology. In fact, the capital stock is sufficiently low that in order for the resource technology to be operated at the optimal resource-capital ratio, resource extraction is restricted. Hence, there is an increase in resource extraction in the first periods. As the capital stock is increased through savings, the restriction on resource extraction is eased and the slope of the extraction path decreases. From period 3 and onwards, there is enough capital to extract the optimal amount of resource, and hence the extraction path slopes downward. In period 5, the capital stock is sufficiently high that the alternative technology is adopted. The resource is abandoned in period 6 . 

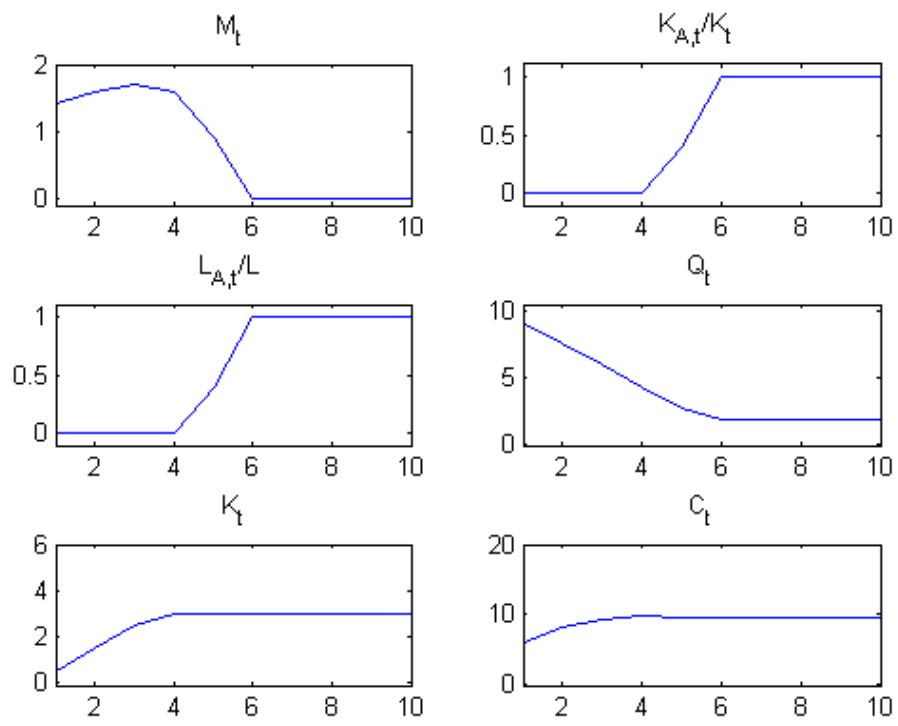

Figure 6. Time paths for initial conditions $K_{0}=0.5$ and $Q_{0}=9$.

The main insights from the two-period model remain when the model is extended to an infinite horizon. If the initial capital stock is high, the alternative technology is adopted immediately and if the initial capital stock is low, the alternative technology is adopted with a delay. The intuition for this result is that if the resource is extracted, capital is first allocated to the resource technology to operate it at the optimal level of capital relative to the resource input. A high resource stock implies that it is desirable to extract more of the resource. If the capital stock is low in relation to the resource stock, all capital will be allocated to the resource technology. Over time, capital is accumulated, the amount of resource extracted relative to capital in the economy decreases, and eventually the capital stock is sufficiently high to adopt the alternative technology.

The infinite horizon model also illustrates how the time path of resource extraction varies with the size of the capital stock in relation to the resource stock. In contrast to the two-period model, the results show that with an infinite horizon, the time path of resource extraction can now be increasing. If the initial capital stock is high, resource extraction is monotonically decreasing over time. However, if the initial capital stock is low, the time path of resource extraction has the shape of an inverse U; it is first increasing and then decreasing. In addition, the resource is abandoned at a later point in time. The initial increase in resource extraction can be explained as follows: the low initial capital stock implies that in order to operate the resource technology at the optimal level of capital relative to the resource input, resource extraction must be restricted. The extraction is instead deferred to future periods, when the capital stock has increased through savings. As capital is accumulated, the restriction on resource extraction is eased. Eventually, the capital stock is sufficiently high to extract the optimal amount of resource and the extraction path starts to slope downward. The deferral of resource extraction to future 
time periods as a result of a low initial capital stock also implies that the resource is abandoned later compared to when the initial capital stock is high.

\section{Industrialization of developing countries}

As described in the introduction, the recent industrialization of large developing countries, such as China and India, has caused an increase in their demand for exhaustible resources, which has had a substantial impact on the world markets for exhaustible resources. In this section, I use the model to try to answer the following question: How are the time path of resource extraction and the adoption of an alternative technology affected by the industrialization of developing countries? The analysis focuses on oil, one of our most important exhaustible resources.

I view the industrialization of developing countries as an increase in their levels of human capital, which results in increases in output. In this model, the contribution of human capital is bundled together with labor in the production function, and hence the labor supply can be viewed as effective labor supply, including human capital. Therefore, industrialization is modeled as an increase in the labor supply of the world economy. Alternatively, one can think of industrialization as an increase in the productivity of the technologies workers use. In this model, it can be expressed as an increase in the parameters $A$ and $B$, which govern productivity of the two technologies. Modeling industrialization as an increase in the productivity of both production technologies would have a comparable effect in this model. The model is calibrated to fit the world production of crude oil, which should be a good proxy for the amount of oil extracted from the ground.

\subsection{Calibration and results}

Figure 7 displays the world production of crude oil in millions of barrels per day over the period 1970-2007. I calibrate the model to the period 1990-2000. Over that period, the increase in the world production of crude oil was 13.2 percent.Hence, the initial values of the capital stock, the resource stock, and the supply of labor are chosen such that the increase in extraction in the model between 1990 and 2000 equals 13 percent. The combination $K_{1990}=0.5, Q_{1990}=10.4$, and $L=15$ generates an increase in the extraction rate equal to 13.3 percent between 1990 and 2000. Given this set of initial conditions, the resulting values of $K_{2000}$ and $Q_{2000}$ are then used to generate time paths for the economy over the period 2000 to $2100^{6}$.

\footnotetext{
${ }^{6}$ Discretization of the state space implies that there exist other combinations of initial conditions which generate an increase in extraction rate of $13 \%$ between 1990 and 2000. They result in very similar time paths for the economy.
} 


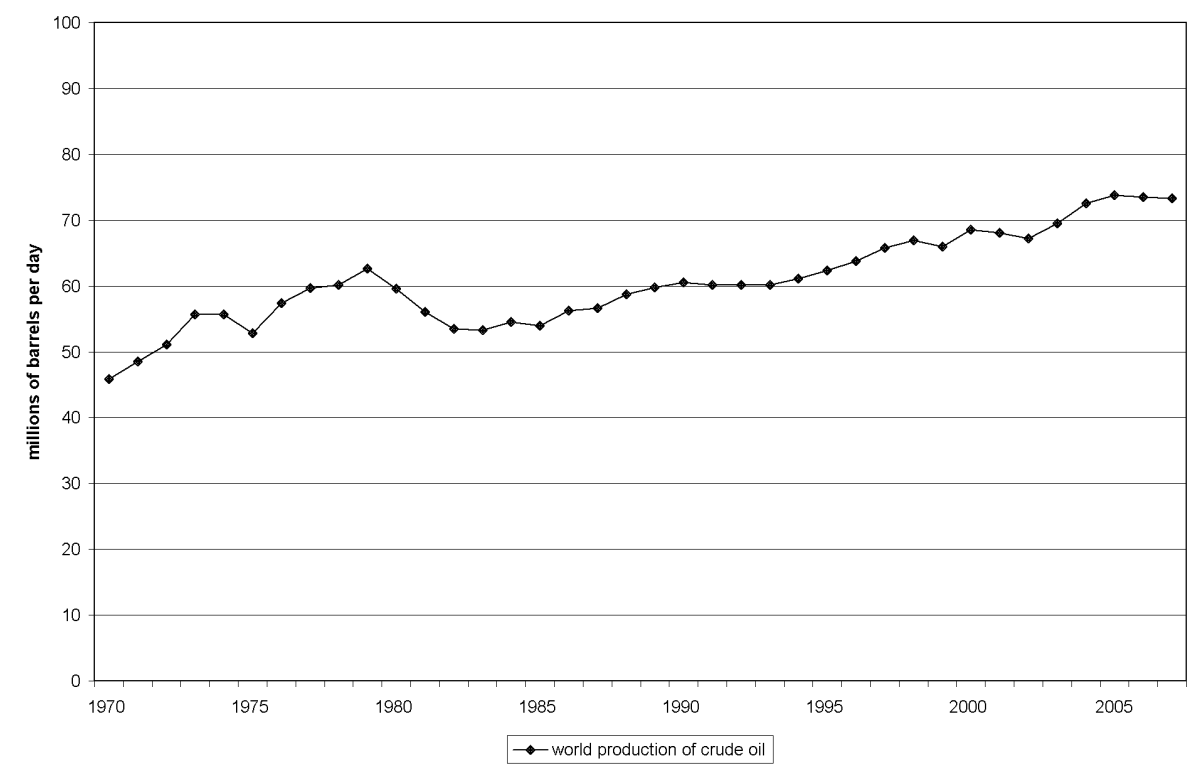

Figure 7. World production of crude oil 1970-2007. Source: International Petroleum Monthly, April 2008, Energy Information Administration.

The time path of the world economy when labor supply is at its initial level $L$ is shown in Figure 8. The calibrated model predicts that the rate of extraction of oil peaks in 2000-2010 and that the alternative technology is adopted in 2040-2050. The two technologies are used simultaneously until oil is abandoned in 2050-2060. I argue that these predictions are broadly in line with forecasts on the trends in future energy supply. As regards the time path for oil extraction, the model does generate a peak in extraction, corresponding to the so-called "peak oil", the point in time when the maximum rate of world oil production is reached. ${ }^{7}$ As regards the model's predictions on adoption of the alternative technology and the abandonment of oil, they correspond roughly to forecasts by the IPCC and Fisher et al. (2006) even though the exact timing differs ${ }^{8}$. I then use this calibration example to analyze the effects of the permanent increase in labor supply; $L^{\prime}>L$, which takes place in the decade 2000-2010. I set $L^{\prime}=19$, which corresponds to an increase in labor supply of about 30 percent.

\footnotetext{
${ }^{7}$ Numerous studies have made forecasts of "peak oil", and estimates vary. See Witze (2007) for an overview. Given the uncertainty surrounding these forcasts, it is difficult to assess the fit of the calibration.

${ }^{8}$ In Sims et al. (2007), the IPCC predicts that hydro power can contribute to $17 \%$ of total electricity generation by 2030 , solar power $1 \%$, and wind power about $7 \%$. Fisher et al. (2006) predict that under a "partnership technology + CCS scenario", roughly $46 \%$ of total electricity in the Asia Pacific Partnership countries (USA, Australia, Japan, China, India, and Korea) will be generated by non-fossil fuels in 2050 .
} 
The time path of the world economy over the time period 2000 to 2100 when labor supply is $L^{\prime}$ is displayed in Figure 8.
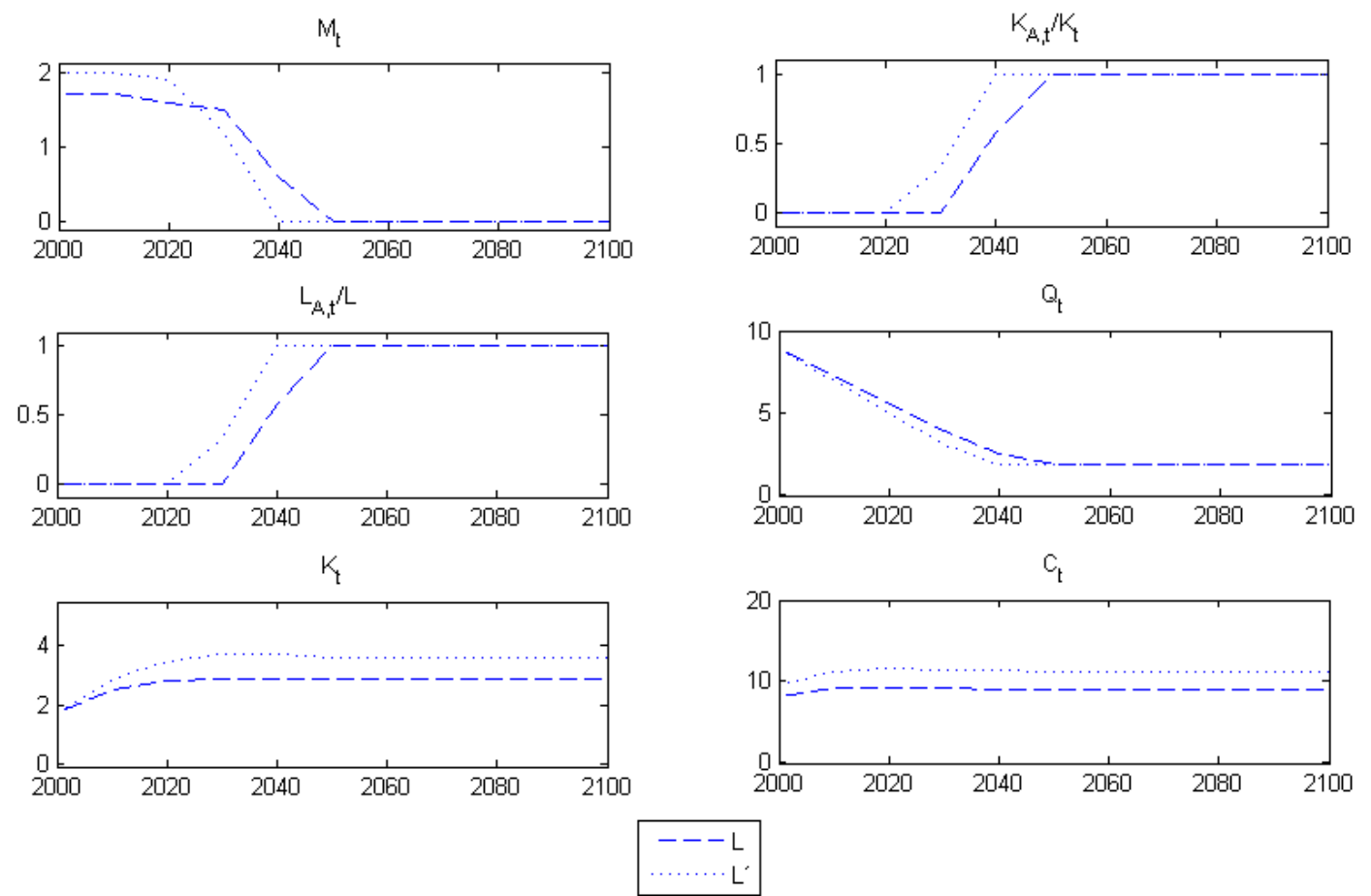

Figure 8. Time paths of the world economy when labor supply is $L$ and $L^{\prime}$.

As a result of the increase in labor supply, the rate of extraction of oil is higher in the first decades, while the total amount of oil extracted is not affected. Most importantly, the alternative technology is adopted a decade earlier. The two technologies are then used simultaneously until oil is abandoned, which occurs a decade earlier. The initial increase in the rate of oil extraction is caused by the increase in output of energy from oil and the change in the steady-state level of capital in the economy which increases capital accumulation. A higher capital stock and an initial increase in the rate of oil extraction both imply that the alternative technology is adopted at an earlier point in time.

One must bear in mind that a factor which affects the use of oil for energy production is the emission of carbon dioxide. Attempts to curb global warming, such as introducing taxes on fossil fuel, emissions trading systems, subsidies to non-fossil energy production etc., increase the costs of producing energy from oil. They can also be expected to intensify developments of alternative technologies for energy production. Both measures can affect the time path of oil extraction and the adoption of alternative technologies. If climate change considerations were incorporated in this model in a way that is constant over time it would have the following effects: the initial calibration example, as shown by the dashed line in Figure 8, would change. However, the qualitative results on the effects of industrialization would not. For example, the 
model shows that the alternative technology is adopted earlier and that oil is abandoned earlier. If climate change considerations are not altered simultaneously with industrialization, these results would still hold.

In addition, I argue that despite the fact that the social planner does not take externalities from fossil fuel use into account, the outcome of one type of efforts to reduce such externalities can still be analyzed in the present model. That is introduction of taxes, emissions trading systems or other ways to increase the cost of emitting carbon dioxide ${ }^{9}$. The introduction of a tax on emissions of carbon dioxide can be interpreted as a decrease in the productivity of the resource technology relative to the alternative technology. This corresponds to a decrease in the parameter $B$, and it would have the following effects. Oil would be abandoned at a higher level of world oil reserves which means that in total, less oil is used and emissions of carbon dioxide decrease. In addition, less capital will be allocated to producing energy from oil since it now has lower productivity relative to alternative technologies such as hydro power and wind power, and these technologies will be adopted sooner than without a tax.

A weakness of this model, which it shares with many other models featuring both exhaustible resources and alternatives, is that it does not account for exploration of new reserves. The entire stock of resource is known at the beginning of time and the optimal time path of extraction is determined on basis of that stock. However, in the case of oil, there is constant exploration for new reserves. In terms of this model, any change in reserves that was unanticipated in the 1990's would imply that optimal decisions are revised during the time period of simulation.

\subsection{Robustness checks}

As described earlier, the parameter $\sigma$ in the extraction cost function is set to 0.5 in the parameterization of the model. This intermediate value was chosen due to lack of empirical estimates. As a robustness check, the model is therefore solved for a range of values: $\sigma \in[0.4,0.6]$. The main results are unaffected by this variation in $\sigma$. A lower value of $\sigma$ increases threshold $\hat{Q}$ and shifts the time path of extraction downwards. When extraction becomes more costly, it is optimal to leave more of the resource in the ground. Conversely, a higher value of $\sigma$ reduces threshold $\hat{Q}$ and and shifts the time path of extraction upwards. In addition, I have performed robustness checks with regard to the productivity of the alternative technology, for $A \in[1.25,1.45]$. A lower productivity implies that the alternative technology is adopted later, oil as an energy source is abandoned later and at a lower level of the remaining stock. Conversely, a higher productivity of the alternative technology implies that it is adopted earlier, oil is abandoned earlier and at a higher level of the remaining stock.

In the model, capital and labor are used in the same proportions in the two technologies. Consequently, the coefficient on capital is $\theta \alpha_{1}$ in the resource technology and $\theta$ in the alternative technology, respectively. $\alpha_{1}<1$ implies a higher coefficient on capital in the alternative technology. To investigate whether that difference could affect the results, I use the following functional form; $G(K, L)=A K_{A}^{\theta_{A}} L_{A}^{1-\theta_{A}}$, where $\theta_{A}=\theta \alpha_{1}$. I find that the main results of the model are robust to this change.

\footnotetext{
${ }^{9}$ Other types of efforts, such as investments in R\&D to reduce emissions of carbon dioxide from fossil fuels cannot be analyzed in this framework, as it does not allow for R\&D investment.
} 


\section{Concluding comments}

What is the optimal path of extraction of exhaustible resources over time? At what point in time will an alternative technology be adopted? How are the time path of extraction and the adoption of the alternative technology affected by the industrialization of developing countries? In this paper, I find that the optimal time paths of resource extraction and technology adoption both depend on the size of the capital stock in relation to the resource stock, as well as on the allocation of capital across the two technologies. The results illustrate the interaction between resource extraction and the economy's capital stock in general equilibrium and underscore the importance of including accumulation of capital over time as well as its allocation within a given time period in models of resource extraction.

The model shows that if the initial capital stock is high in relation to the resource stock, the alternative technology is immediately adopted, and the time path of resource extraction is strictly decreasing. If, instead, the initial capital stock is low in relation to the resource stock, adoption of the alternative technology is delayed. In addition, the time path of resource extraction has the shape of an inverse U: first decreasing and then increasing. This follows from the result that if the resource technology is used it is optimal to allocate capital to that technology first, in order to operate it at a constant resource-capital ratio. A low capital stock in relation to the resource stock implies that there is little capital available in relation to the optimal level of extraction. As a result, both alternative technology adoption and part of resource extraction is deferred to the future, in which more capital has been accumulated. Consequently, the speed of accumulation of capital in the economy affects the speed of adoption of technologies using renewable resources. In the model, capital markets are perfect and savings are directly channeled to capital investments. If that were not the case, a low initial capital stock would imply that adoption of the alternative technology was delayed even further than the current results indicate. Hence, the functioning of capital markets is important for technological change; capital market imperfections reduce capital accumulation and slow down the transition from exhaustible to renewable resources. The International Energy Agency (2008) also emphasizes investments in the transition from fossil fuels to renewables in the global energy sector. In the "ACT scenario", which projects a return of carbon dioxide emissions to current levels by 2050, the International Energy Agency estimates the additional investment needs in the energy sector to be USD 17 trillion. Insufficient access to capital could have a large impact on transitions in such a scenario.

This paper analyzes the effects of industrialization of developing countries on one of our most important exhaustible resources: oil. The model shows that as a result of industrialization of developing countries, the alternative technology for energy production is adopted earlier. Industrialization shifts the path of oil extraction to the present and enlarges the aggregate capital stock, which increases the speed of transition to alternative technologies. Hence, according to this model, the concern that industrialization of developing countries leads to a severe shortage of resources which impedes global production could be unwarranted.

The model presented in this paper features extraction costs that depend not only on extraction flow but also on the resource stock, motivated by a multitude of empirical evidence. This feature indeed 
turns out to influence the results. In the model, stock-dependent extraction costs affect the time paths of resource extraction, and can give a steeper downward slope as a result of the low extraction costs at high levels of the resource stock. It will then be optimal to allocate more capital and labor to the resource technology than would otherwise be the case. Therefore, my conjecture is that late adoption of the alternative technology may occur for higher levels of the capital stock with stock-dependent extraction costs, compared to without. In addition, stock-dependent extraction costs allow for a characterization of the switching point at which the economy goes from using a combination of exhaustible and renewable resources to relying solely on renewable resources. Hence, stock-dependent extraction costs may affect the timing of technology choices such as when to adopt alternative technologies and when to abandon the exhaustible resource. The latter is indeed what Gerlagh (2010) finds in a model where resource owners maximize revenue in the presence of a perfect backstop substitute.

The analysis pertains to a model that is solved for the centralized equilibrium. Hence, it shows the optimal extraction paths and technology choices for the world economy as a whole, when there is cooperation across countries. These results give insights in themselves, but perhaps more importantly, serve as a benchmark for comparison. A drawback is that the analysis does not take into account country differences in resource endowments, nor the behavior of individual countries that act in isolation. Therefore, it would be interesting to carry out the analysis in this paper at the country level as well. An avenue for future research is to extend the model to a world with two countries, a resource-exporting country and a resource-importing country, and analyze how that affects technology choice and extraction paths. In addition, it would be possible to analyze how industrialization of developing countries affects resourceexporters and resource-importers, respectively. The outcome of that analysis could be contrasted to the results presented in this paper, which would then be a natural benchmark.

Another feature of the model is that the productivity of the alternative technology is exogenous. It is reasonable to believe that the productivity can be increased by investment in $\mathrm{R} \& \mathrm{D}$ and that this investment, in turn, depends on the prices of exhaustible resources. The productivity of the alternative technology naturally influences the timing of its adoption. Hence, another avenue for future research is to allow for investment in $\mathrm{R} \& \mathrm{D}$ to increase the productivity of the alternative technology and to analyze how R\&D investment affects technology choice. 


\section{References}

[1] Aghion, P., Howitt, P., 1998. Endogenous Growth Theory, MIT Press, Cambridge.

[2] Australian Bureau of Agricultural and Resource Economics, ABARE, 2008. Australian Commodities, 15 .

[3] Bovenberg, A., Smulders, S., 1995. Environmental quality and pollution-augmenting technological change in a two-sector endogenous growth model. Journal of Public Economics 57, 369-391.

[4] Bretschger, L., 1998. How to substitute in order to sustain: knowledge driven growth under environmental restrictions. Environment and Development Economics 3, 425-442.

[5] Bretschger, L., Smulders, S., 2003. Sustainability and Substitution of exhaustible natural resources: How resource prices affect long-run R\&D investments. CER-ETH Economics working paper 03/26.

[6] Chakravorty, U., Roumasset, J., Tse, K., 1997. Endogenous Substitution Among Energy Resources and Global Warming. Journal of Political Economy 105, 1201-1234.

[7] Cunha-e-Sá, M., Reis, A., 2007. The Optimal Timing of Adoption of a Green Technology. Environmental \& Resource Economics 36, 35-55.

[8] Dasgupta, P., Heal, G., 1974. The Optimal Depletion of Exhaustible Resources. The Review of Economic Studies 41, 3-28.

[9] Dasgupta, P. and Stiglitz, J., 1981. Resource Depletion Under Technological Uncertainty. Econometrica $49,85-104$.

[10] Fisher, B. Ford, M. Jakeman, G. Gurney, A. Penm, J. Matysek, A., Gunasekera, D., 2006. Technological development and economic growth. ABARE Research Report 06.1.

[11] Gerlagh, R., 2010. Too Much Oil. CESifo Economic Studies 57, 79-102.

[12] Goeschl, T., Perino, G., 2007. Innovation without magic bullets: Stock pollution and R\&D sequences. Journal of Environmental Economics and Management 54, 146-161.

[13] Gordon, R., Bertram, M., Graedel, T., 2006. Metal stocks and sustainability. PNAS 103, $1209-1214$.

[14] Grimaud, A., Rouge, L., 2003. Non-renewable resources and growth with vertical innovations: Optimum, equilibrium and economic policies. Journal of Environmental Economics and Management 45, 433-453.

[15] Grimaud, A., Rouge, L., 2008. Environment, Directed Technical Change and Economic Policy. Environmental and Resource Economics 41, 439-463.

[16] Groth, C., Schou, P., 2007. Growth and non-renewable resources: The different roles of capital and resource taxes. Journal of Environmental Economics and Management 53, 80-98. 
[17] Halvorsen, R., Smith, T., 1991. A Test of the Theory of Exhaustible Resources. The Quarterly Journal of Economics 106, 123-140.

[18] International Energy Agency, 2008. Energy Technology Perspectives: Scenarios and Strategies to 2050, Paris, OECD/IEA

[19] Just, R., Netanyahu S., Olson, L., 2005. Depletion of natural resources, technological uncertainty, and the adoption of technological substitutes. Resource and Energy Economics 27, 91-108.

[20] Kamien, M., Schwartz, N., 1978. Optimal Exhaustible Resource Depletion with Endogenous Technical Change. The Review of Economic Studies 45, 179-196.

[21] Krautkraemer, J., 1998. Nonrenewable resource scarcity. Journal of Economic Literature 36, 20652107.

[22] Lin, C., 2008. An Empirical Dynamic Model of OPEC and Non-OPEC. mimeo.

[23] Nordhaus, W., 1973. The Allocation of Energy Resources. Brookings Papers on Economic Activity $1973,529-576$.

[24] Nordhaus W., 1992. Lethal Model 2: The Limits to Growth Revisited. Brookings Papers on Economic Activity 1992, 1-59.

[25] Nordhaus W., Yang, Z., 1996. A Regional Dynamic General-Equilibrium Model of Alternative Climate-Change Strategies. The American Economic Review 86, 741-765.

[26] Pesaran, M., 1990. An Econometric Analysis of Exploration and Extraction of Oil in the U.K. Continental Shelf. The Economic Journal 100, 367-390.

[27] R.E.H. Sims, R.N. Schock, A. Adegbululgbe, J. Fenhann, I. Konstantinaviciute, W. Moomaw, H.B. Nimir, B. Schlamadinger, J. Torres-Martínez, C. Turner, Y. Uchiyama, S.J.V. Vuori, N. Wamukonya, X. Zhang, 2007. Energy supply. In Climate Change 2007: Mitigation. Contribution of Working Group III to the Fourth Assessment Report of the Intergovernmental Panel on Climate Change [B. Metz, O.R. Davidson, P.R. Bosch, R. Dave, L.A. Meyer (eds)], Cambridge University Press, Cambridge, United Kingdom and New York, NY, USA.

[28] Smulders, S., 2000. Economic Growth and Environmental Quality, in: H. Folmer and L. Gabel, (Eds.), Principles of Environmental Economics, Edward Elgar, Cheltenham.

[29] Smulders, S., de Nooij, M., 2003. The impact of energy conservation on technology and economic growth. Resource and Energy Economics 25, 59-79.

[30] Tahvonen, O., Salo, S., 2001. Economic growth and transitions between renewable and nonrenewable energy resources. European Economic Review 45, 1379-1398. 
[31] Tsur, Y., Zemel, A., 2003. Optimal transition to backstop substitutes for nonrenewable resources. Journal of Economic Dynamics \& Control 27, 551-572.

[32] Tsur, Y., Zemel, A., 2005. Scarcity, growth and R\&D. Journal of Environmental Economics and Management 49, 484-499.

[33] Witze, A., 2007. That's oil, folks..., Nature 445.

[34] Young, D., 1992. Cost Specification and Firm Behaviour in a Hotelling Model of Resource Extraction. The Canadian Journal of Economics 25, 41-59. 


\section{Appendix}

\section{A1 Constant returns to scale}

To show that there are constant returns to scale, I multiply the initial stocks with a number $N>1$. If the economy has constant returns to scale, the optimal allocations should be independent of $N$. Suppose therefore that the initial amount of capital is multiplied by $N>0$ and that there are $N$ identical deposits of the exhaustible resource, with initial stock $Q_{1}$, so that initial conditions are the following: the capital stock is $N K_{1}$ and the sum of deposits of the resource stock is $N Q_{1}$. I denote total extraction from all deposits $\bar{M}_{t}$, for $t \in\{1,2\}$. Since all deposits are identical, the optimal extraction will be the same for all of them and hence extraction from each deposit $n \in N$ will then be $M_{t, n}=\frac{\bar{M}_{t}}{N}$. $Q_{t}$ now denotes stock per deposit, and the total resource stock at time $t$ is $N Q_{t}$. Hence, the evolution over time for one deposit is $Q_{t+1}=Q_{t}-\frac{\bar{M}_{t}}{N}$. The total flow cost of extraction from all deposits is $R(M, Q)=N C\left(Q_{t}^{1-\sigma}-\left(Q_{t}-\frac{\bar{M}_{t}}{N}\right)^{1-\sigma}\right)$, which is just the cost per deposit multiplied by the number of deposits.

The optimization problem is now

$$
\begin{aligned}
& \quad \quad \max _{\left\{\bar{M}_{t}, K_{A, t}, L_{A, t}, K_{t+1}\right\}_{t=1}^{2}} c_{1}+c_{2} \\
& \text { s.t. } \\
& \quad N Q_{2}=N Q_{1}-\bar{M}_{t} \\
& c_{1}=A K_{A, 1}+B\left(N K_{1}-K_{A, 1}\right)^{\alpha_{1}} \bar{M}_{1}^{\alpha_{2}} \\
& \quad \quad N C\left(Q_{1}^{1-\sigma}-\left(Q_{1}-\frac{\bar{M}_{1}}{N}\right)^{1-\sigma}\right)-K_{2} \\
& \quad c_{2}=A K_{A, 2}+B\left(K_{2}-K_{A, 2}\right)^{\alpha_{1}} \bar{M}_{2}^{\alpha_{2}} \\
& \quad-N C\left(Q_{2}^{1-\sigma}-\left(Q_{2}-\frac{\bar{M}_{2}}{N}\right)^{1-\sigma}\right) \\
& 0 \leq \bar{M}_{1} \leq N Q_{1}, 0 \leq K_{A, 1} \leq N K_{1}, 0 \leq L_{A, 1} \leq L \\
& 0 \leq \bar{M}_{2} \leq N Q_{2}, 0 \leq K_{A, 2} \leq K_{2}, 0 \leq L_{A, 2} \leq L \\
& c_{1}, c_{2} \geq 0
\end{aligned}
$$

In an interior solution in period $2, \bar{M}_{2}^{*} \in\left(0, N Q_{2}\right)$ and $K_{A, 2}^{*} \in\left(0, K_{2}\right)$ satisfy

$$
\begin{aligned}
\alpha_{2} B\left(K_{2}-K_{A, 2}\right)^{\alpha_{1}} \bar{M}_{2}^{\alpha_{2}-1} & =(1-\sigma) C\left(Q_{2}-\frac{\bar{M}_{2}}{N}\right)^{-\sigma} \\
A & =\alpha_{1} B\left(K_{2}-K_{A, 2}\right)^{\alpha_{1}-1} \bar{M}_{2}^{\alpha_{2}} .
\end{aligned}
$$

Given $\alpha_{1}+\alpha_{2}=1$, the system yields

$$
\frac{\alpha_{2} B^{\frac{1}{1-\alpha_{1}}} \alpha_{1}^{\frac{\alpha_{1}}{1-\alpha_{1}}}}{A^{\frac{\alpha_{1}}{1-\alpha_{1}}}}=(1-\sigma) C\left(Q_{2}-\frac{\bar{M}_{2}}{N}\right)^{-\sigma} .
$$


Solving the system of equations in the baseline model, as given by

$$
\begin{aligned}
\alpha_{2} B\left(K_{2}-K_{A, 2}\right)^{\alpha_{1}} M_{2}^{\alpha_{2}-1} & =(1-\sigma) C\left(Q_{2}-M_{2}\right)^{-\sigma} \\
A & =\alpha_{1} B\left(K_{2}-K_{A, 2}\right)^{\alpha_{1}-1} M_{2}^{\alpha_{2}} .
\end{aligned}
$$

yields

$$
\frac{\alpha_{2} B^{\frac{1}{1-\alpha_{1}}} \alpha_{1}^{\frac{\alpha_{1}}{1-\alpha_{1}}}}{A^{\frac{\alpha_{1}}{1-\alpha_{1}}}}=(1-\sigma) C\left(Q_{2}-M_{2}\right)^{-\sigma}
$$

given $\alpha_{1}+\alpha_{2}=1$. Since the extraction rate for each deposit $n$ is $M_{2, n}=\frac{\bar{M}_{2}}{N},(22)$ is identical to (23) and hence, the allocation is independent of $N$.

In an interior solution in period $1, \bar{M}_{1}^{*} \in\left(0, N Q_{1}\right)$ and $K_{A, 1}^{*} \in\left(0, N K_{1}\right)$ satisfy

$$
\begin{aligned}
& \alpha_{2} B\left(N K_{1}-K_{A, 1}\right)^{\alpha_{1}} \bar{M}_{1}^{\alpha_{2}-1}-(1-\sigma) C\left(Q_{1}-\frac{\bar{M}_{1}}{N}\right)^{-\sigma} \\
= & \beta C(1-\sigma)\left(\left(Q_{1}-\frac{\bar{M}_{1}}{N}-\frac{\bar{M}_{2}}{N}\right)^{-\sigma}-\left(Q_{1}-\frac{\bar{M}_{1}}{N}\right)^{-\sigma}\right) \\
& A=\alpha_{1} B\left(N K_{1}-K_{A, 1}\right)^{\alpha_{1}-1} \bar{M}_{1}^{\alpha_{2}} .
\end{aligned}
$$

Given $\alpha_{1}+\alpha_{2}=1$, the system yields

$$
\frac{\alpha_{2} B^{\frac{1}{1-\alpha_{1}}} \alpha_{1}^{\frac{\alpha_{1}}{1-\alpha_{1}}}}{A^{\frac{\alpha_{1}}{1-\alpha_{1}}}}-(1-\sigma) C\left(Q_{1}-\frac{\bar{M}_{1}}{N}\right)^{-\sigma}=\beta C(1-\sigma)\left(\left(Q_{1}-\frac{\bar{M}_{1}}{N}-\frac{\bar{M}_{2}}{N}\right)^{-\sigma}-\left(Q_{1}-\frac{\bar{M}_{1}}{N}\right)^{-\sigma}\right) .
$$

Solving the system of equations in the baseline model, as given by

$$
\begin{aligned}
& \alpha_{2} B\left(K_{1}-K_{A, 1}\right)^{\alpha_{1}} M_{1}^{\alpha_{2}-1}-(1-\sigma) C\left(Q_{1}-M_{1}\right)^{-\sigma} \\
& =\beta C(1-\sigma)\left(\left(Q_{1}-M_{1}-M_{2}\right)^{-\sigma}-\left(Q_{1}-M_{1}\right)^{-\sigma}\right) \\
& A=\alpha_{1} B\left(K_{1}-K_{A, 1}\right)^{\alpha_{1}-1} M_{1}^{\alpha_{2}} .
\end{aligned}
$$

yields, given $\alpha_{1}+\alpha_{2}=1$,

$$
\frac{\alpha_{2} B^{\frac{1}{1-\alpha_{1}}} \alpha_{1}^{\frac{\alpha_{1}}{1-\alpha_{1}}}}{A^{\frac{\alpha_{1}}{1-\alpha_{1}}}}-(1-\sigma) C\left(Q_{1}-M_{1}\right)^{-\sigma}=\beta C(1-\sigma)\left(\left(Q_{1}-M_{1}-M_{2}\right)^{-\sigma}-\left(Q_{1}-M_{1}\right)^{-\sigma}\right) .
$$

Since $M_{1, n}=\frac{\bar{M}_{1}}{N}$ and $M_{2, n}=\frac{\bar{M}_{2}}{N},(24)$ is identical to (25) and hence, the allocation is independent of $N$. 


\section{A2 Proofs}

\section{Proof of Proposition 1}

Suppose that extraction is $M=\epsilon$ where $\epsilon \rightarrow 0$. Inserting (19) into the expression for consumption gives $c=A\left(K-\left(\frac{A}{\alpha_{1} B \epsilon^{\alpha_{2}}}\right)^{\frac{1}{\alpha_{1}-1}}\right)+B\left(\frac{A}{\alpha_{1} B \epsilon^{\alpha_{2}}}\right)^{\frac{\alpha_{1}}{\alpha_{1}-1}} \epsilon^{\alpha_{2}}-R(\epsilon, Q)$. By defining $D_{0}=A K$ and $D_{1}=-A\left(\frac{A}{\alpha_{1} B}\right)^{\frac{1}{\alpha_{1}-1}}+B\left(\frac{A}{\alpha_{1} B}\right)^{\frac{\alpha_{1}}{\alpha_{1}-1}}$, consumption can be written as $c=D_{0}+D_{1} \epsilon^{\frac{\alpha_{2}}{1-\alpha_{1}}}-R(\epsilon, Q)$. We get that $\frac{\partial c}{\partial \epsilon}=\frac{\alpha_{2}}{1-\alpha_{1}} D_{1} \epsilon^{\frac{\alpha_{2}}{1-\alpha_{1}}-1}-\frac{\partial R(\epsilon, Q)}{\partial \epsilon}$. Now, if $\alpha_{1}+\alpha_{2}=1$, then $\frac{\partial c}{\partial \epsilon}=\frac{\alpha_{2}}{1-\alpha_{1}} D_{1} \epsilon^{0}-\frac{\partial R(\epsilon, Q)}{\partial \epsilon}$. If $\lim _{\epsilon \rightarrow 0} \frac{\partial R(\epsilon, Q)}{\partial \epsilon}>\frac{\alpha_{2}}{1-\alpha_{1}} D_{1}$, it follows that $\frac{\partial c}{\partial \epsilon}<0$, and it is optimal to set $M^{*}=0 . \lim _{\epsilon \rightarrow 0} \frac{\partial R(\epsilon, Q)}{\partial \epsilon}=\frac{C(1-\sigma)}{Q^{\sigma}}$. Hence, there exists a $\hat{Q}>0$, such that $\frac{C(1-\sigma)}{\hat{Q}^{\sigma}}>\frac{\alpha_{2}}{1-\alpha_{1}} D_{1}$. An interior solution to the optimization problem in period 1 satisfies (18) and (19). Solving for $K_{1}-K_{A, 1}$ from (19) and inserting it in (18) gives $\frac{\alpha_{2} B^{\frac{1}{1-\alpha_{1}}} \alpha_{1}^{\frac{\alpha_{1}}{1-\alpha_{1}}} M^{\frac{\alpha_{1}+\alpha_{2}-1}{1-\alpha_{1}}}}{A^{\frac{\alpha_{1}}{1-\alpha_{1}}}}=(1-\sigma) C\left(Q_{1}-M_{1}\right)^{-\sigma}+\beta C(1-\sigma)\left(Q_{1}-M_{1}-M_{2}\right)^{-\sigma}-\beta C(1-\sigma)\left(Q_{1}-M_{1}\right)^{-\sigma}$. Now, if $\alpha_{1}+\alpha_{2}=1$ and $\beta=1$, the expression simplifies to $\frac{\alpha_{2} B^{\frac{1}{1-\alpha_{1}}} \alpha_{1}^{\frac{\alpha_{1}}{1-\alpha_{1}}}}{A^{\frac{\alpha_{1}}{1-\alpha_{1}}}}=C(1-\sigma)\left(Q_{1}-M_{1}-M_{2}\right)^{-\sigma}$. Solving for $M_{1}^{*}+M_{2}^{*}$ yields $M_{1}^{*}+M_{2}^{*}=Q_{1}-\frac{A^{\frac{\alpha_{1}}{\sigma\left(1-\alpha_{1}\right)}} C \frac{1}{\sigma}(1-\sigma)^{\frac{1}{\sigma}}}{\alpha_{2}^{\frac{1}{\sigma}} B^{\frac{1}{\sigma\left(1-\alpha_{1}\right)}} \alpha_{1}^{\overline{\sigma\left(1-\alpha_{1}\right)}}} \cdot M_{1}^{*}+M_{2}^{*}=0$ if $Q_{1}=\hat{Q}$, where $\hat{Q}=\frac{A^{\frac{\alpha_{1}}{\sigma\left(1-\alpha_{1}\right)}} C^{\frac{1}{\sigma}}(1-\sigma)^{\frac{1}{\sigma}}}{\alpha_{2}^{\frac{1}{\sigma}} B^{\frac{1}{\sigma\left(1-\alpha_{1}\right)}} \alpha_{1}^{\overline{\sigma\left(1-\alpha_{1}\right)}}}$.

\section{Proof of Proposition 2}

If $K_{2}>\hat{K}\left(Q_{2}\right)$, it follows that $K_{A, 2}^{*}>0$ and $K_{A, 1}^{*}=0$ or $K_{A, 1}^{*}>0$. As long as $K_{A, 1}^{*}>0$, it follows from Proposition 1 that $M_{1}^{*}+M_{2}^{*}=Q_{1}-\hat{Q}$. Now, suppose that $K_{A, 1}^{*}=0$. $M_{2}^{*}$ is given by $M_{2}^{*}=Q_{2}-\frac{A^{\frac{\alpha_{1}}{\sigma\left(1-\alpha_{1}\right)}} C^{\frac{1}{\sigma}}(1-\sigma)^{\frac{1}{\sigma}}}{\alpha_{2}^{\frac{1}{\sigma}} B^{\frac{1}{\sigma\left(1-\alpha_{1}\right)}} \alpha_{1}^{\overline{\sigma\left(1-\alpha_{1}\right)}}}$, but by definition, $Q_{2}=Q_{1}-M_{1}^{*}$. Consequently, $M_{1}^{*}+M_{2}^{*}$ is given by $M_{1}^{*}+M_{2}^{*}=Q_{1}-\frac{A^{\frac{\alpha_{1}}{\sigma\left(1-\alpha_{1}\right)}} C^{\frac{1}{\sigma}}(1-\sigma)^{\frac{1}{\sigma}}}{\alpha_{2}^{\frac{1}{\sigma} B^{\frac{1}{\sigma\left(1-\alpha_{1}\right)}}} \alpha_{1}^{\overline{\sigma\left(1-\alpha_{1}\right)}}}$.

\section{Proof of Proposition 3}

If $K_{1}>\hat{K}\left(Q_{1}\right)$, it follows that $K_{A, 1}^{*}>0$. Hence, $M_{1}^{*}+M_{2}^{*}=M^{T}$. If $Q_{1}>\hat{Q}$ it follows that $M^{T}>0$. Given that $Q_{2} \leq Q_{1}$, it must be the case that $K_{A, 2}^{*}>0$. Since the optimal solution only determines $M^{T}$ and not the division into $M_{1}^{*}$ and $M_{2}^{*}, M_{1}^{*}$ can take any value in $\left[0, M^{T}\right]$ and the utility of the consumer is maximized. Then, $M_{2}^{*}=M^{T}-M_{1}^{*}$.

\section{Proof of Proposition 4}

The condition $Q_{1}>\hat{Q}$ implies that $M_{1}^{*}+M_{2}^{*}>0$. The condition $K_{2}>\hat{K}\left(Q_{2}\right)$ implies that $M_{1}^{*}+M_{2}^{*}=$ $M^{T}$. The optimal amount of saving given $M_{1}=\tilde{M}$ is: $K_{2}=\frac{A K_{1}}{\alpha_{1}}-C\left(Q_{1}^{1-\sigma}-\left(Q_{1}-\tilde{M}\right)^{1-\sigma}\right)$, and next period's resource stock is $Q_{2}=Q_{1}-\tilde{M}$. For $M_{1}=\tilde{M}, K_{A, 1}^{*}=0$ and since $K_{2}>\hat{K}\left(Q_{2}\right)$, we have that $K_{A, 2}^{*}>0$. For $M_{1}<\tilde{M}, K_{A, 1}^{*}>0$. If the resulting $K_{2}$ and $Q_{2}$ are such that $K_{2}<\hat{K}\left(Q_{2}\right)$, then $K_{A, 2}^{*}=0$. Otherwise, $K_{A, 2}^{*}>0$. Hence, the allocations are either $K_{A, 1}^{*}=0, K_{A, 2}^{*}>0$ or $K_{A, 1}^{*}>0$, 
$K_{A, 2}^{*}=0$ or $K_{A, 1}^{*}>0, K_{A, 2}^{*}>0 . K_{1} \leq \hat{K}\left(Q_{1}\right)$ is equivalent to $\tilde{M}<M^{T}$. This implies that $M_{2}^{*}>0$ for all $M_{1}$, since $M_{2}^{*}=M^{T}-M_{1}^{*}$. Is $M_{1}^{*}>0$ ? Suppose that $M_{1}^{*}=0$, then $Q_{2}=Q_{1}$ and, given $A=1$, $K_{2}=K_{1}$. But then $K_{2}<\hat{K}\left(Q_{2}\right)$. Consequently, $M_{1}=0$ implies that $K_{A, 2}=0$ and then utility is not maximized. Therefore, $M_{1}^{*}>0$ and $M_{2}^{*}>0$.

\section{Proof of Proposition 5}

The condition $Q_{1}>\hat{Q}$ implies that $M_{1}^{*}+M_{2}^{*}>0$. Since $K_{2} \leq \hat{K}\left(Q_{2}\right)$, Proposition 2 does not hold, and we have that $M_{1}^{*}+M_{2}^{*}<M^{T}$. Therefore, it follows from the first-order conditions that it cannot be optimal to set $K_{A, 1}^{*}>0$. Hence, $M_{1}^{*}>0$ and $K_{A, 1}^{*}=0$. Similarly, it cannot be optimal to allocate capital to the alternative technology in period 2 , and $M_{2}^{*}>0$ and $K_{A, 2}^{*}=0$.

\section{A3 Numerical solution method for the infinite time horizon}

For the purpose of solving the model for an infinite time horizon, the social planner's maximization problem is recast in a recursive manner, with value function $V(K, Q)$ and policy functions $E_{i}(K, Q)$, $i \in\left\{Q^{\prime}, K_{A}, L_{A}, K^{\prime}\right\}$, where $Q^{\prime}$ and $K^{\prime}$ are next period's resource stock and capital stock, respectively. This is a stationary problem and therefore, the value function and the policy functions are independent of time. The optimization problem is

1. $\forall(K, Q), V(K, Q)$ solves

$$
\begin{aligned}
& \begin{array}{l}
V(K, Q)=\max _{Q^{\prime}, K_{A}, L_{A}, K^{\prime}}\left(\log (c)+\beta V\left(K^{\prime}, Q^{\prime}\right)\right) \\
\text { s.t. } \\
\begin{aligned}
c= & A K_{A}^{\theta} L_{A}^{1-\theta}+B\left(\left(K-K_{A}\right)^{\theta}\left(L-L_{A}\right)^{1-\theta}\right)^{\alpha_{1}} M^{\alpha_{2}} \\
& \quad-C\left(Q^{1-\sigma}-\left(Q^{\prime-\sigma}\right)-K^{\prime}\right.
\end{aligned} \\
M=Q-Q^{\prime}
\end{array}
\end{aligned}
$$

2. $\forall(K, Q), E_{i}(K, Q)=\arg \max _{i} V(K, Q), i \in\left\{Q^{\prime}, K_{A}, L_{A}, K^{\prime}\right\}$.

The social planner has four choice variables; $Q^{\prime}$ (which is equivalent to choosing this period's extraction rate $M), K_{A}, L_{A}$, and $K^{\prime}$. They are chosen so as to maximize the right-hand side of the expression for $V(K, Q)$ for all values of $K$ and $Q$.

The model is solved using discretization of the state space and backward induction methods. The discretization of the state space implies that the social planner can choose next period's resource stock $Q^{\prime}$ and capital stock $K^{\prime}$ in discrete amounts $Q^{\prime} \in \boldsymbol{Q}$ and $K^{\prime} \in \boldsymbol{K}$, where $\boldsymbol{Q}$ and $\boldsymbol{K}$ are grids $\left[Q^{1}<Q^{2}<\ldots<\right.$ $\left.Q^{N}\right]$ and $\left[K^{1}<K^{2}<\ldots<K^{N}\right]$. There are natural limits on the lower endpoints; $Q^{1}=0$ and $K^{1}=0$. Since the sequence $\left\{Q_{t}\right\}_{t=0}^{\infty}$ is weakly decreasing, $Q^{N}$ can be set to the maximum initial value for which the model is to be solved. $K^{N}$ must be set such that it well exceeds the steady-state level of capital when the resource is abandoned. 
The backward induction solution method is then applied as follows. Starting from the last time period, $T$, the value function $V(K, Q, T)$ and the policy functions $E_{i}(K, Q, T)$ are given by the last period solution to the two-period problem. Using $V(K, Q, T)$ and $E_{i}(K, Q, T)$, it is possible to solve backwards for the optimal policy functions $E_{i}(K, Q, T-\tau)$ and value function $V(K, Q, T-\tau)$ for each grid point in the two-dimensional grid, for $\tau=1, \ldots, T$. As in the two-period model, both interior and corner solutions exist. The backward-solving procedure is repeated until $\|V(K, Q, T-\tau)-V(K, Q, T-\tau-1)\|<\epsilon \forall(K, Q)$, where $\epsilon$ is a small number. 